\title{
The Critical Care Society of Southern Africa Consensus Statement on ICU Triage and Rationing (ConICTri)
}

\author{
G M Joynt, ${ }^{1} \mathrm{MB}$ BCh; P D Gopalan, ${ }^{2} \mathrm{MB}$ ChB; A Argent, ${ }^{3} \mathrm{MB} \mathrm{BCh}, \mathrm{MD} ; \mathbf{S}$ Chetty, ${ }^{4} \mathrm{MB} \mathrm{ChB}, \mathrm{PhD} ; \mathbf{R}$ Wise, ${ }^{5} \mathrm{MB}$ ChB; V K W Lai, ${ }^{1} \mathrm{PhD}$; \\ E Hodgson, ${ }^{6} \mathrm{MB}$ BCh; A Lee,${ }^{1} \mathrm{PhD} ; \mathrm{I}$ Joubert, ${ }^{7} \mathrm{MB}$ BCh; S Mokgokong, ${ }^{8} \mathrm{MB}$ BCh; S Tshukutsoane, ${ }^{9} \mathrm{BCur}$; G A Richards, ${ }^{10} \mathrm{MB} \mathrm{BCh}, \mathrm{PhD}$; \\ C Menezes, ${ }^{911} \mathrm{MD}$, PhD; L R Mathivha, ${ }^{10} \mathrm{MB} \mathrm{ChB}$; B Espen, ${ }^{12}$ CCRN; B Levy, ${ }^{13} \mathrm{MB} \mathrm{ChB} ; \mathbf{K}$ Asante, ${ }^{14} \mathrm{PhD} ; \mathbf{F}$ Paruk, ${ }^{15} \mathrm{MB} \mathrm{ChB}, \mathrm{PhD}$ \\ ${ }^{1}$ Department of Anaesthesia and Intensive Care, The Chinese University of Hong Kong, Hong Kong \\ ${ }^{2}$ Department of Anaesthesiology and Critical Care, School of Clinical Medicine, University of KwaZulu-Natal, Durban, South Africa \\ ${ }^{3}$ Department of Paediatrics and Child Health, University of Cape Town, South Africa \\ ${ }^{4}$ Department of Anaesthesiology and Critical Care, Stellenbosch University, Cape Town, South Africa \\ ${ }^{5}$ Department of Anaesthesiology and Critical Care, School of Clinical Medicine, University of KwaZulu-Natal, Durban, and Edendale Hospital, \\ Pietermaritzburg, South Africa \\ ${ }^{6}$ Department of Anaesthesiology and Critical Care, School of Clinical Medicine, University of KwaZulu-Natal, Durban, and Inkosi Albert Luthuli \\ Central Hospital, Durban, South Africa \\ ${ }^{7}$ Department of Anaesthesia and Peri-operative Medicine, University of Cape Town and Groote Schuur Hospital, Cape Town, South Africa \\ ${ }^{8}$ Department of Neurosurgery, University of Pretoria, South Africa \\ ${ }^{9}$ Chris Hani Baragwanath Academic Hospital, Soweto, Johannesburg, South Africa \\ ${ }^{10}$ Department of Critical Care, Faculty of Health Sciences, University of the Witwatersrand, Johannesburg, South Africa \\ ${ }^{11}$ Department of Internal Medicine, Faculty of Health Sciences, University of the Witwatersrand, Johannesburg, South Africa \\ ${ }^{12}$ Centre for Health Professions Education, Stellenbosch University, Cape Town, South Africa \\ ${ }^{13}$ Netcare Rosebank Hospital, Johannesburg, South Africa \\ ${ }^{14}$ African Organization for Research and Training in Cancer, Cape Town, South Africa \\ ${ }^{15}$ Department of Critical Care, University of Pretoria, South Africa
}

Corresponding author: G M Joynt (gavinmjoynt@cuhk.edu.hk)

\begin{abstract}
Background. In South Africa (SA), intensive care is faced with the challenge of resource scarcity as well as an increasing demand for intensive care unit (ICU) services. ICU services are expensive, and practitioners in low- to middle-income countries experience daily the consequences of limited resources. Critically limited resources necessitate that rationing and triage (prioritisation) decisions are frequently necessary in SA, particularly in the publicly funded health sector.

Purpose. The purpose of this consensus statement is to examine key questions that arise when considering the status of ICU resources in SA, and more specifically ICU admission, rationing and triage decisions. The accompanying guideline in this issue is intended to guide frontline triage policy and ensure the best utilisation of intensive care in SA, while maintaining a fair distribution of available resources. Fair and efficient triage is important to ensure the ongoing provision of high-quality care to adult patients referred for intensive care.

Recommendations. In response to 14 key questions developed using a modified Delphi technique, 29 recommendations were formulated and graded using an adapted GRADE score. The 14 key questions addressed the status of the provision of ICU services in SA, the degree of resource restriction, the efficiency of resource management, the need for triage, and how triage could be most justly implemented. Important recommendations included the need to formally recognise and accurately quantify the provision of ICU services in SA by national audit; actively seek additional resources from governmental bodies; consider methods to maximise the efficiency of ICU care; evaluate lower level of care alternatives; develop a triage guideline to assist policy-makers and frontline practitioners to implement triage decisions in an efficient and fair way; measure and audit the consequence of triage; and promote research to improve the accuracy and consistency of triage decisions. The consensus document and guideline should be reviewed and revised appropriately within 5 years.

Conclusion. In recognition of the absolute need to limit patient access to ICU because of the lack of sufficient intensive care resources in public hospitals, recommendations and a guideline have been developed to guide policy-making and assist frontline triage decision-making in SA. These documents are not a complete plan for quality practice but rather the beginning of a long-term initiative to engage clinicians, the public and administrators in appropriate triage decision-making, and promote systems that will ultimately maximise the efficient and fair use of available ICU resources.
\end{abstract}

S Afr Med J 2019;109(8):613-629. https://doi.org/10.7196.SAMJ.2019.v109i8b.13947 | S Afr J Crit Care 2019;35(1):36-52. https://doi.org/10.7196/SAJCC.2019.v35.i1b.383

\section{Introduction}

The intensive care unit (ICU) is defined as a designated area where close monitoring and life support treatments are provided for patients with potential or established organ failure. The ICU therefore provides a higher level of care and facilities than the general wards or intermediate care units, with such care being delivered by 
specially trained staff. ${ }^{[1]}$ For the purposes of the present document, critical care refers to care provided in an ICU.

Internationally, intensive care is faced with the challenge of resource scarcity and an exponentially increasing demand for ICU services. ${ }^{[2-5]}$ ICU services are expensive and, although limited literature exists to quantify the burden of critical illness and resource scarcity in low- and middle-income countries (LMICs), practitioners in LIMCs experience daily the consequences of these limited resources. The motivation for this consensus statement is the universal experience of ICU practitioners in South Africa (SA) that as a consequence of critically limited resources, rationing and triage (prioritisation) decisions are frequently necessary, particularly in the publicly funded health sector. The development of a consensus statement and guideline for intensive care practitioners is intended to facilitate these decisions. These documents are important to ensure the ongoing provision of high-quality care to adult patients referred for intensive care. The recommendations and processes should provide for both the best utilisation of intensive care in $\mathrm{SA}$, and the fair distribution of available resources. By promoting improved and consistent standards in decision-making practice, we aim to both protect and guide administrators and clinicians when faced with these difficult clinical and ethical challenges, and provide transparency to the public as to how decisions are made. ${ }^{[6]}$

The purpose of this consensus statement is to examine key questions that arise when considering the status of ICU resources in SA, and more specifically ICU admission, rationing and triage decisions in the South African context. The expert consensus group aimed to summarise current evidence and provide consensus-based recommendations addressing these questions. This statement is accompanied by a clinical practice guideline ${ }^{[7]}$ that provides a framework to inform frontline triage policy and ensure the best utilisation of intensive care in SA, while maintaining the fair distribution of available resources.

\section{Methods}

The consensus statement and grading of the quality of practice guidelines were developed using the Appraisal of Guidelines for Research \& Evaluation Instrument (AGREE II) ${ }^{[8]}$

\subsection{Definitions}

The term 'triage' is derived from the French word meaning 'to sort. Triage, in the context of intensive care medicine (ICM), describes the process of prioritisation of patients for admission when available resources are insufficient to satisfy all needs or requests for admission. Triage has the potential of denying admission to a patient who might benefit from intensive care, in favour of another who is deemed to be of higher priority. ${ }^{[9]}$

\subsection{Participants}

Participants in the consensus meeting were recruited from the Critical Care Society of Southern Africa (CCSSA) by the chairperson of the CCSSA Congress held in Sun City on $19-22$ October 2017, and the President of the CCSSA (FP and IJ). The invited participants (Appendix 1) included intensive care specialists and intensive care nurses from public and private healthcare institutions with experience or research record in triage, including those with an interest in bioethics, hospital administrators and a member of the legal profession. An intensivist with clinical experience in triage, and previous involvement in triage research and international consensus processes, was invited to chair the round-table meeting (GJ).

\subsection{Target population}

The consensus recommendations and guideline were developed to inform decision-making for adult patients referred for ICU admission.

\subsection{Target audience}

The target audience was doctors, nurses and other healthcare professionals caring for severely ill patients who may require ICU admission on a day-to-day basis, as well as hospital administrators and governmental bodies with jurisdiction over healthcare matters.

\subsection{Key question development and Delphi process}

The consensus statement recommendations were developed using a Delphi process prior to the face-to-face round-table consensus meeting on 18 October 2017. Key questions related to current principles and practice regarding admission, rationing and triage were drafted by the meeting co-chairs in early April 2017 (GJ and FP). Between April and July 2017, a modified Delphi process, ${ }^{[10]}$ using REDCap (Research Electronic Data Capture), a secure web application hosted at The Chinese University of Hong Kong, was undertaken during which all invited participants progressively modified, deleted or added questions. Questions were retained if approved by $80 \%$ or more of participants in the current form. Questions not receiving 80\% approval were modified on the basis of participant suggestions, and subjected to a further round of voting. Failure to secure $80 \%$ consensus after modification and 3 rounds of voting resulted in elimination of a question. Once no further questions were proposed, and repeated voting failed to significantly change consensus percentages, 14 key questions were finalised for review and discussion at the face-to-face consensus meeting. To facilitate an appropriate review of the question and provide evidence to support consensus recommendations in response to the key questions, a literature review was conducted.

\subsection{Literature search}

In August 2017, each key question identified by the Delphi process was formulated into a population, intervention, comparison, outcomes (PICO) format, or abstracted to 'key search terms' as appropriate by $\mathrm{VL}$, assisted and supervised by GJ and AL. A search of the electronic databases (OVID MEDLINE January 1946 - August 2017) and OVID EMBASE January 1910 - August 2017) was made. The medical subject headings and text words used for the search strategy, developed with help from the Chinese University of Hong Kong (CUHK) medical librarian, included the following: 'health care rationing', 'intensive care units', 'patient admission, 'patient discharge', 'patient selection', 'policy making,' 'practice guidelines', 'practice patterns, physicians', 'private sector,' 'public sector,' 'quality of health care, 'refusal to treat', 'resource allocation', 'resuscitation orders', 'south africa' and 'triage'. The search yielded a total of 1917 articles for screening. Where more than 10 articles were identified for a specific question, we exported the results into Covidence systematic review software (Veritas Health Innovation, Melbourne, Australia). The participants were divided into pairs to address the evidence related to specific questions. Each 
pair was allocated questions broadly matching areas of interest and expertise. Each pair of allocated expert participants constituted a panel and independently screened the articles for their allocated question to establish relevance. Non-relevant articles were eliminated. Where there was disagreement, a consensus decision was reached by direct correspondence or discussion.

\subsection{Evidence summary and recommendations}

Between August and October 2017, the expert panel members summarised available evidence, and formulated draft recommendations arising from each question. These summaries were presented and discussed by all participants during the morning of a full-day face-to-face round-table meeting at Sun City prior to the annual CCSSA scientific meeting on 18 October 2017. The principles of the GRADE approach were used to formulate and report recommendations and levels of evidence. ${ }^{[11,12]}$ After discussion, preliminary consensus was reached on all summaries and recommendations.

Recommendations were classified as strong (grade 1), weak (grade 2) or ungraded, based on an assessment of the quality of available evidence, the balance between desirable and undesirable effects, considerations of competing values and preferences, and an assessment of the outcomes achieved for the magnitude of resource use. ${ }^{[12,13]}$ Grading (A to D) for the quality of evidence supporting a recommendation was given to reflect the certainty of evidence underlying the recommendation (Table 1).

The first draft of the consensus statement was completed after collation of summaries and graded recommendations, and development of the proposed guideline. The consensus statement was circulated by email to all members for comment in April and May 2018. All authors approved the final draft statement by email circulation.

\subsection{Open external consultation}

The final draft of the consensus recommendations was made openly available on the CCSSA website https://www.criticalcare.org.za/ ConICTri/Whatis from August 2018 for 3 months, and CCSSA members (nurses, doctors, allied health and industry) were invited to review and comment on the proposed draft. The site was also open to public view and participation. The consensus statement with relevant open external consultation additions included was circulated to all invited participants in December 2018 for final approval.

\subsection{Guideline review}

A review of the existing recommendations and accompanying guideline should occur 5 years after publication of this document, and be implemented by the guideline development group of CCSSA, unless an earlier revision is mandated by emerging high-quality medical evidence. The updated statement and guideline should, where possible, incorporate findings from an audit of implementation data as described in Table 3.

\section{Results}

Question development and a 3-round Delphi process resulted in 14 key questions. The 14 key questions addressed the status of the provision of ICU services in SA, the degree of resource restriction, the efficiency of resource management, the need for triage, and how triage could be most justly implemented. Recommendations arising from the evidence summary and conclusions drawn were formulated. Open consultation feedback resulted in 2 additional resources being reviewed and the additional information appropriately referenced. All opinions received via the website were positively aligned with the consensus conclusions and recommendations. A summary of key questions and graded recommendations is provided (Table 2).

\begin{tabular}{|c|c|c|}
\hline Recommendation & Quality of evidence supporting recommendation & Interpretation \\
\hline $\begin{array}{l}1 \text { (Strong) } \\
\text { Benefits strongly outweigh } \\
\text { burdens and/or costs }\end{array}$ & $\begin{array}{l}\text { A (High) } \\
\text { Future research unlikely to change confidence in } \\
\text { current known findings }\end{array}$ & $\begin{array}{l}\text { Recommendation should be implemented by relevant } \\
\text { parties. } \\
\text { In a clinical setting, most patients should receive this } \\
\text { therapeutic decision. }\end{array}$ \\
\hline $\begin{array}{l}1 \text { (Strong) } \\
\text { Benefits strongly outweigh } \\
\text { burdens and/or costs }\end{array}$ & $\begin{array}{l}\text { B (Moderate) } \\
\text { Future research may change confidence in current } \\
\text { known findings }\end{array}$ & $\begin{array}{l}\text { Recommendation should be implemented by relevant } \\
\text { parties. } \\
\text { In a clinical setting, most patients should receive this } \\
\text { therapeutic decision. Recommendations may change with } \\
\text { better-quality evidence. }\end{array}$ \\
\hline $\begin{array}{l}1 \text { (Strong) } \\
\text { Benefits strongly outweigh } \\
\text { burdens and/or costs }\end{array}$ & $\begin{array}{l}\mathrm{C}(\text { Low }) \\
\text { Future research likely to change confidence in current } \\
\text { known findings }\end{array}$ & $\begin{array}{l}\text { Implementation should be considered by relevant parties. } \\
\text { In a clinical setting, most patients should receive this } \\
\text { therapeutic decision. Recommendations likely to change } \\
\text { with better-quality evidence. }\end{array}$ \\
\hline $\begin{array}{l}2 \text { (Weak) } \\
\text { Uncertainty over balance of } \\
\text { burdens and/or costs }\end{array}$ & $\begin{array}{l}\text { A (High) } \\
\text { Future research unlikely to change confidence in } \\
\text { current known findings }\end{array}$ & $\begin{array}{l}\text { Implementation may be considered by relevant parties. } \\
\text { In a clinical setting, decision-making may differ from } \\
\text { recommendation depending on individual circumstances }\end{array}$ \\
\hline $\begin{array}{l}2 \text { (Weak) } \\
\text { Uncertainty over balance of } \\
\text { burdens and/or costs }\end{array}$ & $\begin{array}{l}\text { B (Moderate) } \\
\text { Future research may change confidence in current } \\
\text { known findings }\end{array}$ & \multirow{2}{*}{$\begin{array}{l}\text { Implementation may be considered by relevant parties. } \\
\text { In a clinical setting, decision-making may differ from } \\
\text { recommendation depending on individual circumstances } \\
\text { and future research. }\end{array}$} \\
\hline $\begin{array}{l}2 \text { (Weak) } \\
\text { Uncertainty over balance of } \\
\text { burdens and/or costs }\end{array}$ & $\begin{array}{l}\text { C (Low) } \\
\text { Future research likely to change confidence in current } \\
\text { known findings }\end{array}$ & \\
\hline Ungraded & $\begin{array}{l}\mathrm{D} \text { (Very low) } \\
\text { Insufficient evidence to support a recommendation }\end{array}$ & $\begin{array}{l}\text { Recommendation based solely on consensus view of } \\
\text { participants. Future research is required. }\end{array}$ \\
\hline
\end{tabular}




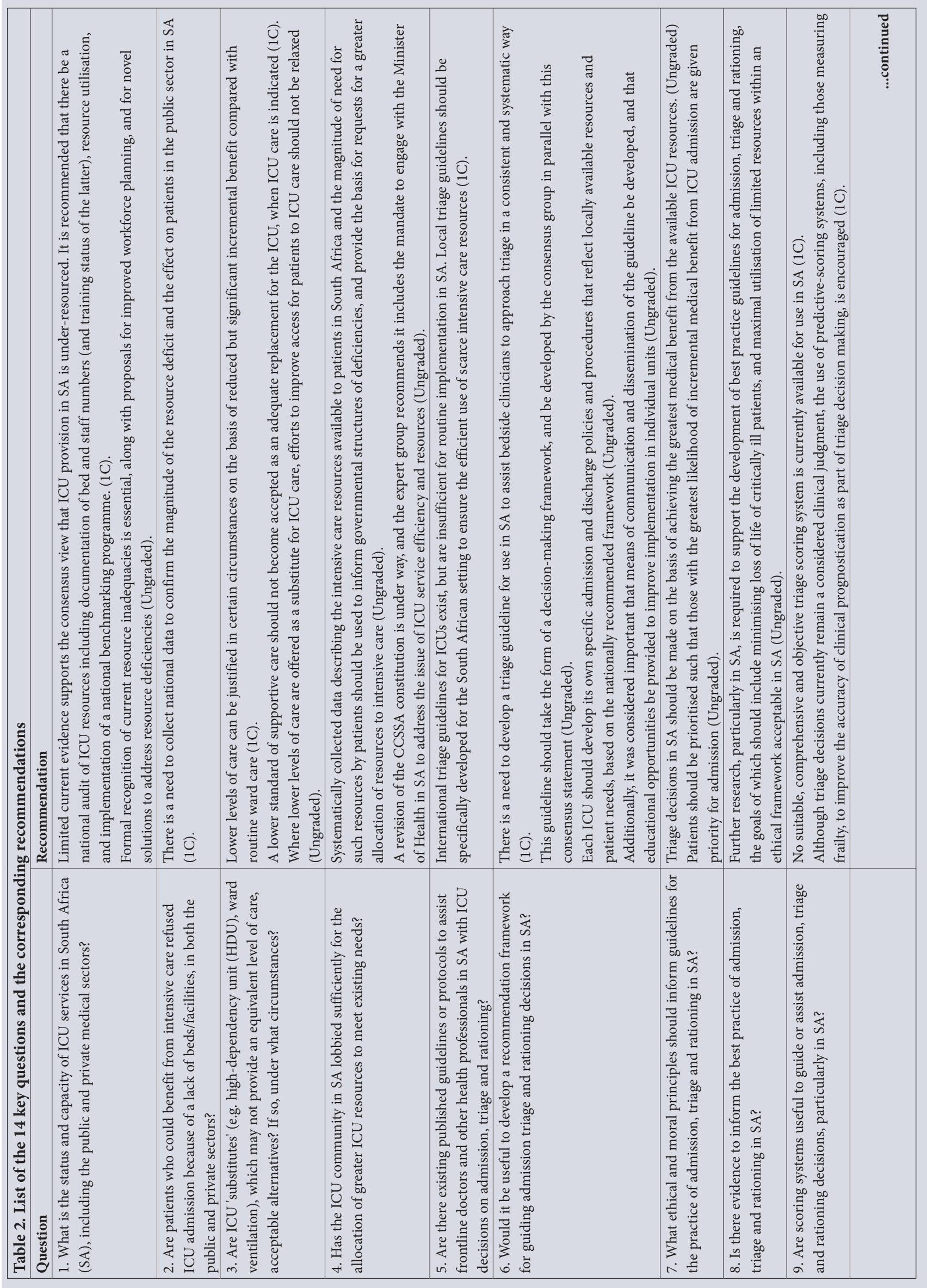




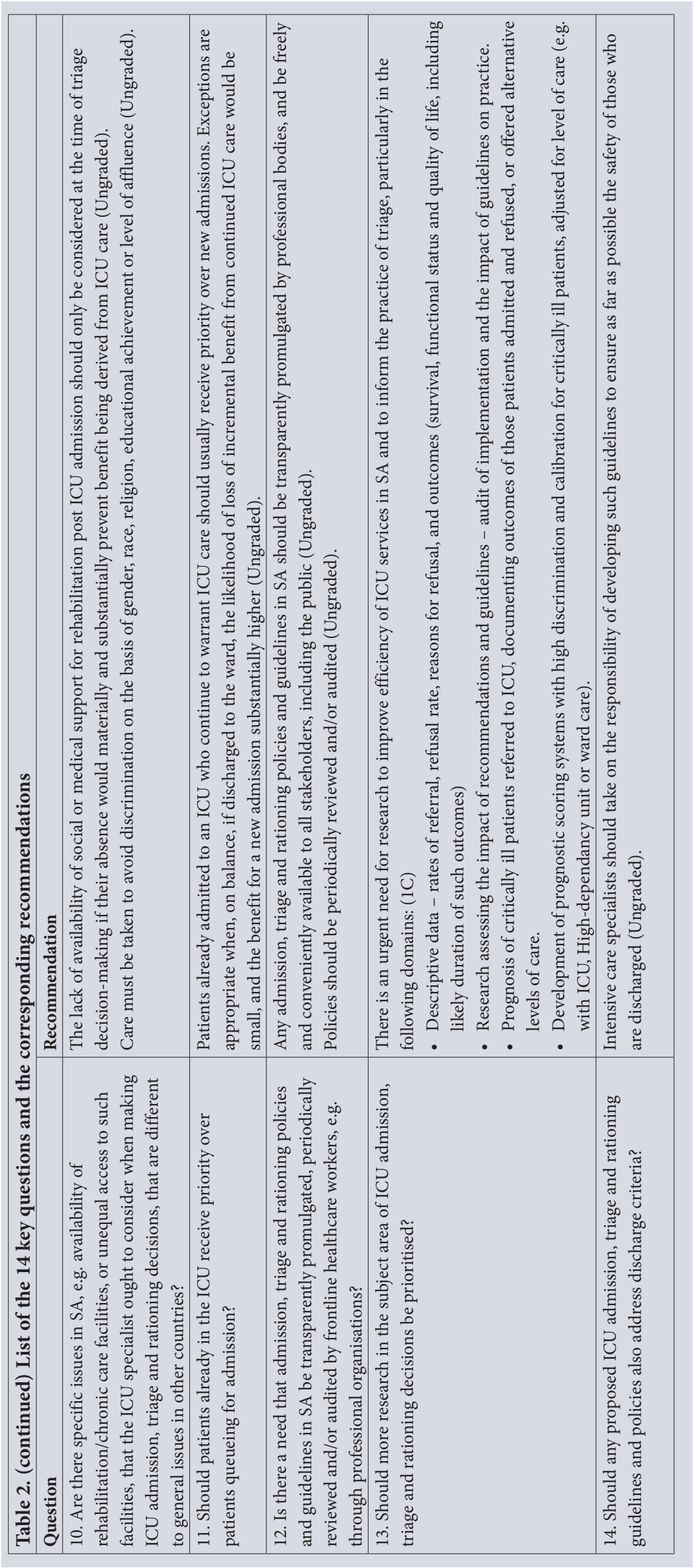

\subsection{What is the status and capacity of ICU services in SA, including the public and private medical sectors? \\ Evidence summary}

Healthcare services are accessed by 55.9 million South Africans ${ }^{[14]}$ and are unequally distributed across 9 provinces, and between the private and public health sectors. There is, however, limited information available that accurately describes the status of provision of ICU services. Using a predictive score, Burch et al. ${ }^{[15]}$ classified $25.1 \%$ of their medical admissions as warranting admission to an intensive care service; however, a follow-up survey showed that only $16 \%$ of all medical admissions were admitted to an ICU. ${ }^{[16]}$ A description of adult surgical ICU admissions in public hospitals in SA showed that the ICU admission rate $(6.5 \%)$ was lower than comparable international rates, and that those who were admitted had a substantially higher mortality. The authors interpreted the data to indicate a lack of intensive care resources and that those who were admitted were sicker. ${ }^{[17]}$

A national audit of ICU resources conducted under the auspices of the CCSSA more than a decade ago, ${ }^{[18]}$ also demonstrated an uneven distribution of ICU beds across provinces, and between the public and private sectors. ${ }^{[19]}$ Approximately $23 \%$ of public, and $84 \%$ of private, hospitals had intensive care or high-care (HC) units. Of a national total of 4168 ICU and HC beds, $43 \%$ were in the public sector, with the remaining $57 \%$ in the private sector. Approximately $18 \%$ of these were HC beds, of which $27 \%$ were located in general wards. The ICU bed-to-acute-hospital-bed ratio was 1.7\% in the public sector, compared with a more favourable and internationally comparable $8.9 \%$ in the private sector. While overall ICU bed-topopulation ratios in SA are in the mid-range by international comparison, ${ }^{[4]}$ the majority of these beds are found in the private health sector, accessible to a minority of the population. Data derived from Naidoo et al. ${ }^{[20]}$ indicate an ICU bed-to-population ratio in the public sector of 2.4 per 100000 , well below international norms. ${ }^{[4]}$ The majority of $\mathrm{HC}$ units were located in public tertiary level hospitals.

In a subsequent audit 4 years later, Naidoo et al. ${ }^{[20]}$ confirmed the unequal distribution of ICU beds, reporting that of a total of 4719 ICU and $\mathrm{HC}$ beds, $25 \%$ were in the public, and $75 \%$ in the private, sector. The ICU bed-to-totalhospital-bed ratio was $2.2 \%$ in the public sector, compared with $14.3 \%$ in the private sector.

Three provinces (Gauteng, Western Cape and KwaZulu-Natal) accounted for $\sim 80 \%$ of all intensive 


\begin{tabular}{|l|l|}
\hline Table 3. Selected key audit metrics relevant to quality assurance and performance improvement when performing triage \\
\hline $\begin{array}{l}\text { ICU utilisation and } \\
\text { performance metrics }\end{array}$ & $\begin{array}{l}\text { Total number of ICU admissions including a severity of illness score, referral source and referral specialty } \\
\text { ICU occupancy (mean daily occupancy rate, number of days with no available beds, etc.) } \\
\text { ICU length of stay, unplanned re-admission rates } \\
\text { Adjusted/standardised mortality rates }\end{array}$ \\
\hline Triage & $\begin{array}{l}\text { Number of emergency referral patients refused admission or admission delayed } \\
\text { Number of elective surgical referral patients refused or delayed } \\
\text { Reasons for delayed admission or refusals, including admission priority ranking* } \\
\text { Number of critically ill patients transferred in and out of the hospital and reasons for transfer } \\
\text { Number of conflicts, e.g. with patient/family members or healthcare professionals }\end{array}$ \\
\hline Discharge & $\begin{array}{l}\text { Number of after-hours discharges } \\
\text { Delayed discharge and reasons for delayed discharge (e.g. no beds in ward) }\end{array}$ \\
\hline Triage policy & $\begin{array}{l}\text { Compliance - availability of written policy, availability of designated triage personnel, number of instances of } \\
\text { violation of triage policy and nature of violations }\end{array}$ \\
\hline $\begin{array}{l}\text { Reasons for refusal should allow differentiation between refusal imposed by limited resources (triage) and other reasons such as patients for whom ICU would not be of benefit (alternatively } \\
\text { termed futility), e.g. patient is not sufficiently ill to warrant admission, or too severely ill, and highly likely to die even with ICU admission See the clinical practice guideline }{ }^{7]} \text { for a detailed } \\
\text { discussion. }\end{array}$ \\
\hline
\end{tabular}

care beds. ${ }^{[19,20]}$ The Western Cape had the best ratio of public ICU beds to population (1:14 000 to 1:20 000), and Limpopo the worst (1:82 000 to $1: 150000) .{ }^{[19,20]}$ These ratios probably under-represent the disparity as they did not account for the likely use of private services by the more affluent urban populations of the Western Cape and Gauteng. Despite the limited access of the majority of the population to private sector ICU care, of a total of 244024 patients who were admitted to all units in SA during 2002, 63\% were to private units, and the remainder to the public sector. ${ }^{[21]}$

The national audit also reported on intensive care nursing resources. ${ }^{[22]}$ The number of full-time nurses employed per functional ICU bed was reported as 1.1 to 1 , and only $25.6 \%$ of nurses were ICUtrained. These are both substantially below international norms and guidelines that recommend 1 to 1 bedside nursing for mechanically ventilated patients at all times, resulting in nurse employment per bed ratios in excess of 5 to 1 , and expect a minimum of $50 \%$ of nursing staff to be ICU trained. ${ }^{[23,24]}$ Recent data suggest that low nurse-to-patient ratios may be associated with higher mortality. ${ }^{[25-28]}$ In addition, ICU nursing managers had an average of only 12.8 years of ICU experience, with less than $75 \%$ being ICU-trained.

The number of trained ICU specialists (intensivists) in SA is unknown, as many intensivists have either not registered their intensive care qualification with the Health Professions Council of SA, or are not currently practising in SA. Since the recognition of ICU specialist training almost 2 decades ago, 113 intensivists have been certified in the specialty by The Colleges of Medicine of SA. It is believed by the expert group that there are substantially less practising in SA currently and number $\sim 50-75$. A recent consensus conference in North America strongly recommended that patients in an ICU be managed on a day-to-day basis by an intensivist, a view increasingly supported by empirical evidence of increased efficiency and improved outcomes. ${ }^{[29-32]}$ Given the small number of certified intensivists in SA, meeting this benchmark is clearly not possible. There are no national or regional benchmarking programmes in SA, and consequently reliable evaluation of the quality of care offered in South African ICUs is not possible.

In conclusion, limited current evidence indicates that there are significant resource shortages in terms of ICU bed numbers in SA compared with high-middle-income countries especially in public sector hospitals, with a large discrepancy across various regions.
In addition, there is a substantial shortage of trained nurses and intensivists. Reliable data evaluating resource provision are dated and sparse.

\section{Recommendation}

Limited current evidence supports the consensus view that ICU provision in SA is under-resourced. It is recommended that there be a national audit of ICU resources including documentation of bed and staff numbers (and training status of the latter), resource utilisation, and implementation of a national benchmarking programme (1C).

Formal recognition of current resource inadequacies is essential, along with proposals for improved workforce planning, and for novel solutions to address resource deficiencies (Ungraded).

\subsection{Are patients who could benefit from intensive care refused ICU admission because of a lack of beds/ facilities, in both the public and private sectors?}

There are limited South African data available to answer this question directly. An audit of requests for admission to the ICU at a regional public sector hospital in Durban between March and June 1993 revealed 264 requests, ${ }^{[33]}$ of whom only $140(53 \%)$ were admitted. Of the 124 (47\%) remaining patients, 56 (21\%) were refused admission because the ICU was full. Another 47 (18\%) were refused on the basis that ICU care was deemed to be futile and, in the remaining $22(8 \%)$, it was believed that the patient could be safely treated in the ward. A retrospective analysis of the referral records encompassing 3 sampling periods over 5 years at 2 public sector ICUs in Durban, identified refusal rates of $38 \%$ for Hospital 1 and $22 \%$ for Hospital 2. Of these refusals, $55 \%$ and $89 \%$, respectively, were as a direct consequence of no bed being available. ${ }^{[34]}$ In a more recent audit at a regional public sector hospital in Gauteng, a refusal rate for ICU admission of $65 \%$ was reported. Reasons for refusal were reported as the patient being too ill (40\%), too well (30\%) and lack of ICU resources (30\%). ${ }^{[35]}$

Using a severity of illness score, Burch et al.$^{[15]}$ classified $25.1 \%$ of their medical admissions over a 10-month period as warranting admission to an intensive care service; however, only $9 \%$ of medical admissions were managed in the HC unit, suggesting that a large number of patients who should have been managed in an intensive care or high-dependency unit were managed in the general ward. 
Argent et al. ${ }^{[36]}$ described the pressure on admissions to their 26-bed paediatric ICU to justify the implementation of an admission policy. They particularly described the frequent need to cancel elective surgery to facilitate emergency admissions. A recent retrospective review of referrals and triage patterns in a South African metropolitan adult intensive care service consisting of 2 ICUs in KwaZulu-Natal reported that they had received 2081 patient referrals, of which $72.0 \%$ ( $n=1499 / 2$ 081) were accepted and planned for admission, and $28.0 \%(n=582 / 2081)$ refused. ${ }^{[37]}$ Of the patients accepted, $60.7 \%$ ( $n=910 / 1499$ ) experienced delays prior to admission, and $37.4 \%$ ( $n=561 / 1499)$ were never actually admitted to the ICU. Those who were refused were either considered too well $(53.6 \% ; n=312 / 582)$ or too ill ( $46.4 \% ; n=270 / 582)$ to benefit from ICU care.

Comprehensive national published data are lacking. In particular, there are no published data from the private sector. The provision of private medical ICUs in SA requires full payment for service (either personally or via medical insurance). This model creates a circumstance whereby bed and staff numbers expand to meet the demand as the resource is fully funded. Immediate bed unavailability, in the face of an emergency, is usually facilitated by transfer to another unit, and delay or refusal of ICU care is rare (personal communication).

In conclusion, while comprehensive data are lacking and conclusions are susceptible to publication bias, all published data report that patients who may benefit from ICU care are refused admission because of shortages of resources in the public sector. The personal experience of the expert panel is that the limited available data published, accurately represent day-to-day practice across the country. Patients in private hospitals are invariably admitted to an ICU when a request is made, in contrast to the situation in the public sector.

\section{Recommendation}

There is a need to collect national data to confirm the magnitude of the resource deficit and the effect on patients in the public sector in SA (1C).

\subsection{Are ICU 'substitutes' (e.g. high-dependency unit (HDU), ward ventilation), which may not provide an equivalent level of care, acceptable alternatives? If so, under what circumstances?}

In general, patients who are referred for, and refused, ICU care have an excess mortality, even when adjusted for severity of illness. ${ }^{[38-47]}$ The magnitude of this difference is substantial, with a combined odds ratio (OR) of death of approximately three times, according to a meta-analysis of studies in which triage was employed. ${ }^{[48]}$ It is possible that some of these deaths were in patients in whom therapy was deemed to be futile. However, even a delayed admission, because the unit was currently full, was associated with increased morbidity and mortality. ${ }^{[49-51]}$

Because resources are chronically scarce, many hospitals in SA provide mechanical ventilation and other life support therapies, which are generally reserved for the ICU, in high-dependency units or the general wards. For some less severely ill patients, lower levels of care may be appropriate; however, for patients who require ICU care (but where it is unavailable due to resource constraints), outcomes from lower-intensity environments are worse than those expected if patients were able to access full ICU care ${ }^{[52,53]}$ However, even a reduced benefit, where no alternative exists, may still be beneficial. Other expert groups concur that if ICU beds are not available, efforts should be made to provide the best care possible in settings outside of the ICU, and that hospitals provide alternative solutions for patients in need of monitoring or life support. ${ }^{[54]}$ Understanding which patients may benefit most from such alternatives may also be important in the triage process, as lower levels of care may be appropriate, and even have advantages over ICU care, for selected patient groups. For example, chronic obstructive pulmonary disease (COPD) patients managed with mechanical ventilation, even if invasive, in the general ward seem to have some reasonable prospect of deriving benefit, while those post cardiac arrest and with severe physiological disturbances do not. ${ }^{[52,53,55]} \mathrm{A}$ recent non-randomised, prospective cohort study demonstrated that patients with COPD eligible for management with non-invasive mechanical ventilation had similar outcomes whether treated in an ICU, HDU or a designated general ward area. ${ }^{[56]}$ The cost of achieving this outcome was significantly lower in the ward. Similarly, comparatively less sick postoperative patients, who were denied postoperative HDU care because of resource restrictions, had a shorter hospital stay and similar outcomes to those admitted, in contrast with those who were more ill, who appeared to derive significant benefit from admission. ${ }^{[57,58]}$ These observations highlight the need to allocate patients to appropriate and cost-effective levels of care. This process is well addressed by recent North American admission, discharge and triage guidelines, ${ }^{[29]}$ which were primarily concerned with the allocation of patients to appropriate levels of care. It must be highlighted that these studies examining lower levels of care were not conducted in the South African setting, and if lower levels of care are similarly utilised, they should be provided for patients most likely to benefit, and by appropriately trained staff in properly adapted environments.

In conclusion, while an intermediate level of care (e.g. ward mechanical ventilation or HDU care) may deliver improved incremental benefit compared with ward care, failure to be admitted to an ICU when indicated probably results in excess morbidity and mortality when compared with ICU care.

\section{Recommendation}

Lower levels of care can be justified in certain circumstances on the basis of reduced, but significant, incremental benefit compared with routine ward care (1C).

A lower standard of supportive care should not become accepted as an adequate replacement for the ICU, when ICU care is indicated (1C). Where lower levels of care are offered as a substitute for ICU care, efforts to improve access for patients to ICU care should not be relaxed (Ungraded).

\subsection{Has the ICU community in SA lobbied sufficiently for the allocation of greater ICU resources to meet existing needs?}

The need for triage and rationing is a direct consequence of insufficient ICU resources. Throughout the world, countries face difficult questions regarding access to, delivery of, and payment for expensive healthcare services such as ICU. This question necessarily 
requires a decision regarding the proportion of healthcare expenditure that should be apportioned to intensive care services. ${ }^{[59]}$ The lack of sufficient resources in the public health sector has been described above. A recent expert consensus document on ICU triage achieved high agreement for the statement that despite the practical need to ration scarce resources fairly, 'physicians should remain staunch advocates of their patients' best interests. ${ }^{\text {[59] }}$ In this regard, intensive care practitioners have a societal responsibility to identify systematic resource shortfalls, inform relevant administrative and governing institutions of societal expectations, and justifiably seek improved resource allocation. The recent Durban Declaration clearly sets out many of these responsibilities, and states that it is a basic human right for all people nationwide to have access to intensive care services. ${ }^{[60]}$

The principal national body representing intensive care doctors, nurses and healthcare professionals allied to intensive care services in SA is the CCSSA. The CCSSA cooperates closely with the HPCSA to regulate the practice of intensive care and maintain standards. Initiatives to improve resource allocation have been attempted by the CCSSA by engaging in discussion with the Minister of Health in 2010.

In conclusion, limited efforts to improve resource allocation to intensive care services in SA have been made.

\section{Recommendation}

Systematically collected data describing the intensive care resources available to patients in SA and the magnitude of need for such resources by patients should be used to inform governmental structures of deficiencies, and provide the basis for requests for a greater allocation of resources to intensive care (Ungraded).

A revision of the CCSSA constitution is under way, and the expert group recommends it includes the mandate to engage with the Minister of Health in SA to address the issue of ICU service efficiency and resources (Ungraded).

\subsection{Are there existing published guidelines or protocols to assist frontline doctors and other health professionals in SA with ICU decisions on admission, triage and rationing?}

The Society of Critical Care Medicine, and the American Thoracic Society in North America, have provided consensus statements and guidance that have been periodically updated. ${ }^{[29,54,61]}$ Consequently, most ICUs in the USA (up to $88 \%$ in academic centres) have established local guidelines, although regular use of these guidelines was reported in only $25 \%$ of units. ${ }^{[2]}$ A recent report from an internationally diverse task force of the World Federation of Societies of Intensive and Critical Care Medicine provided some general guidance for intensivists performing triage decisions. ${ }^{[63]}$ Consensus-based triage guidelines and statements that could potentially be implemented during outbreaks and disasters have also been published. ${ }^{[64-66]}$ In SA, there are no published guidelines for admission, discharge and triage of adult patients, or published reports of any of individual hospital practice guidelines. The expert group was aware of only scattered units with such guidelines. A single published admission guideline in SA was specifically directed at the paediatric population. ${ }^{[36]}$

A review of the international guidelines revealed that while many sound principles and practice recommendations were articulated, the guidelines were primarily concerned with the allocation of patients to available levels of care in circumstances different from the resourcerestricted South African environment. ${ }^{[29,61]}$ The World Federation guidance was overly general and was restricted to providing guidance relevant only to certain components of the triage process. ${ }^{[63]}$ Consensusbased triage guidelines and statements that could potentially be implemented during outbreaks and disasters are informative, ${ }^{[64-66]}$ but are not easily translatable to routine practice. For example, in outbreaks, the epidemic disease is frequently uniform in presentation and prognosis, a circumstance quite different from routine ICU practice where diagnoses are varied and to a large extent random. Nevertheless, some important concepts consistently emerge and most expert groups have recommended an approach that favours policy based on improved incremental benefit (utilitarianism) rather than egalitarian principles. The former favours the use of decision-making support systems, stresses the importance of prognostication so that any expected benefit can be most accurately estimated, emphasises that final triage decision-making should be in the hands of senior and experienced intensivists, and recognises that good communication and transparency are essential. ${ }^{[59,63]}$

In conclusion, high-quality published guidelines on admission, triage and rationing exist in other countries and regions; however, they have been developed for circumstances different from those routinely experienced in SA, particularly in the public health sector, where the resource restriction is persistent and severe, and distribution of resources uneven.

\section{Recommendation}

International triage guidelines for ICUs exist, but are insufficient for routine implementation in SA. Local triage guidelines should be specifically developed for the South African setting to ensure the efficient use of scarce intensive care resources (1C).

\subsection{Would it be useful to develop a recommendation framework for guiding admission triage and rationing decisions in SA?}

As established in the answers to questions 1 and 2, in the public sector in SA, the demand for ICU services exceeds supply, which frequently results in refusal of admission of patients based only on bed availability. Question 5 addressed the issue of existing guidelines and published protocols, and determined that there was a lack of published guidelines suitable for use in South African conditions. A call for the need to adopt triage principles in SA, targeting those patients who would benefit most, was made recently. ${ }^{[67]}$

The World Federation Task Force report confirmed that triage protocols and algorithms may be useful, but qualified this statement by adding that final decisions should always be made by skilled intensivists, with collaborative input from multidisciplinary sources when appropriate. ${ }^{[63]}$ The publication of recommendations and guidelines with subsequent passive dissemination has been demonstrated to have beneficial effects on clinical practice, and they are increasingly utilised by the medical community internationally. ${ }^{[68,69]}$ When actively implemented, clinical practice guidance and protocols have been shown to improve patient outcomes. ${ }^{[0,71]}$ Similar guidance in the form of a recommended framework for triage is likely to promote consistency in decisionmaking, provide support for practitioners in this difficult area and 
improve professional practice. ${ }^{[72]}$ While evidence supporting the use of conceptual frameworks and algorithms in the specific setting of triage is scarce, a recent study demonstrated that utilisation of a decisionmaking algorithm compared with intuitive decision-making, resulted in better correlation between decisions made by triage doctors and an improved correlation with reference standard decisions. ${ }^{[73]}$ Expert groups on triage in emergency settings have also recommended that clinical decision support systems or 'tools for application of guidance', rather than clinical judgment alone, should be used. ${ }^{[59,66]}$

A nationally recommended framework to guide institutional policy has other potential advantages in promoting fairness. Opinions of individual healthcare providers generally reflect the values and opinions of those individuals rather than those of the community at large, and therefore they alone should not intuitively make decisions to limit ICU care on the basis of cost to society, ${ }^{[5,61]}$ but these should rather be based on a framework proposed by a wider group. Such an approach should also decrease the influence of personal biases or conflicts of interest. It decreases the risk that individual healthcare providers might try to conserve resources on an ad hoc individual patient basis at the possible expense of another patient's best interests. In the setting of rationing and triage, it has been recommended that responsibility be expressed in the form of institutional policies so that individual doctors are not put into the conflicting role of best serving their own patients, while still trying to consider the needs of other patients. ${ }^{[61]}$

The mere development and publication of guidelines does not guarantee that practice will become aligned with the guideline, ${ }^{[74-76]}$ as documented by a failure of French intensivists to adhere to then contemporary guidelines, although those evaluated had been developed by North American practitioners. ${ }^{[42]}$ Nevertheless, clinical practice may still be improved by ensuring the appropriateness of guidelines to local practice conditions, ${ }^{[42]}$ encouragement of individual hospitals to adapt the guidelines into local policies and providing active educational processes to accompany the guidelines.

\section{Recommendation}

There is a need to develop a triage guideline for use in SA to assist bedside clinicians to approach triage in a consistent and systematic way (1C).

This guideline should take the form of a decision-making framework, and be developed by the consensus group in parallel with this consensus statement (Ungraded).

Each ICU should develop its own specific admission and discharge policies and procedures that reflect locally available resources and patient needs, based on the nationally recommended framework (Ungraded).

Additionally, it was considered important that means of communication and dissemination of the guideline be developed, and that educational opportunities be provided to improve implementation in individual units (Ungraded).

\subsection{What ethical and moral principles should inform guidelines for the practice of admission, triage and rationing in $\mathrm{SA}$ ?}

Admission criteria to ICU in the South African setting have been proposed by the CCSSA. ${ }^{[77]}$ Patients with respiratory failure requiring support with mechanical ventilation, or those with multiorgan failure, or those who require intensive monitoring with the potential need for interventions only available within the ICU, should be considered for admission. Resource restrictions in SA, however, prevent admission of all patients meeting these criteria. All the ethical considerations that follow make the assumption that triage decisions are made on medical health grounds only and without any consideration of patient gender, race, personal beliefs, social standing or socio-economic condition.

The American Society of Critical Care Medicine task force on values, ethics and rationing in critical care defines rationing as the allocation of potentially beneficial healthcare services to some individuals in the face of limited availability that necessarily involves the withholding of those services from other individuals. ${ }^{[29]}$ Triage is the process of prioritisation of patients to receive such rationed healthcare services. In the context of intensive care, doctors making triage decisions must choose who will receive potentially life-saving care and who will not. Because the decision frequently has life-or-death consequences, it weighs heavily on those making the decision. It is therefore important that those making triage decisions understand the triage process they implement and the ethical principles and moral values upon which they are made. These values include the desire to preserve human life and to protect or improve health, to use available intensive care resources efficiently, and to distribute available intensive care resources equitably, while respecting personal dignity, maintaining the therapeutic relationship and protecting the least well-off. ${ }^{[78]}$ However, because resources are finite, and limited, some generally accepted healthcare values such as autonomy, and fidelity, or loyalty, to the individual patient, that are normally so much part of the doctor-patient relationship, have to be forgone. ${ }^{[79]}$ The balancing of values that can be preserved and those that must be forgone generally align with the principled approach to understanding the needs of triage proposed by Beauchamp and Childress. ${ }^{[80]}$ In the presence of absolute resource limitation, it clearly requires that the principle of (distributive) justice be met, whereas the principle of respecting individual autonomy must be forgone. The principle of beneficence (which focuses on our moral obligation to promote good for the individual patient), and non-maleficence (avoidance of actions that may cause individual harm), must also necessarily be sacrificed for some patients. ${ }^{[80]}$ Thus justice, in the setting of resource limitation, creates a direct conflict with the values of the traditional doctorpatient relationship, which require the patient's interests to be the first concern.

Even accepting the above reasoning, achieving efficiency and distribution of resources fairly may be extremely difficult. In particular, the principles of efficiency (the best outcome from use of a resource) and fair distribution (equal access if there is a chance to benefit) are frequently in conflict. ${ }^{[81]}$ Reasonable people often disagree, and provide both rational and sensitive counter-arguments. ${ }^{[82]}$ For example, during an influenza pandemic, some would argue that ventilators be allocated only to those with the best chance of survival (thus maximising the medical benefit derived from the strained resource), but others may feel that ventilators should be allocated on a first-come, first-served basis to all those with a significant but lesser chance of benefit, thus offering some chance of salvage to a broader group of patients. Recent international consensus guidance addressing this particular issue in the intensive care setting has favoured maximisation of efficiency, calling on an 
essentially utilitarian justification for prioritising admissions to intensive care (and access to mechanical ventilation) on the basis of likely incremental benefit. ${ }^{[2,63,65,66]}$ Even if we accept this latter view as acceptable or the best guidance that is currently available, it must be acknowledged that conflict exists between health maximisation in the aggregate and legitimate concerns about equity. For this reason, the American Thoracic Society Bioethics Task Force has recommended an egalitarian (to each individual an equal chance) approach - provided that at least some benefit will accrue from ICU care. In other words, a first-come, first-served basis for ICU admission was recommended. ${ }^{[61]}$

Patients may be refused ICU admission for reasons other than triage. It is generally accepted that doctors are not obliged to provide treatments that are non-beneficial or, in older terminology, futile. ${ }^{[83,84]}$ When considering declining access to life-sustaining treatment on the basis of futility, great care must be taken. Futile or non-beneficial care is a concept that is easily understood but difficult to determine clinically. It has been suggested that non-beneficial or futile interventions are those that have been demonstrated to be effective in less than 1 in 100 attempts. ${ }^{[83]} \mathrm{A}$ recent international consensus statement defined futile therapies strictly as those that were not able to achieve immediate physiological goals, and those that were highly unlikely to gain meaningful health advantages for the patient and thus were an inappropriate form of care. ${ }^{[84]}$ It can be seen that refusal of care on such grounds is likely to be a rare occurrence. It was agreed by the participants that the majority of patients refused admission in SA in the presence of restricted resources would not meet criteria for futility. Consequently the justification for triage must rely primarily on the argument of maximisation of medical benefit for available resources described previously, and choosing individual patients likely to derive greater incremental benefit. Thus, unlike refused patients for whom ICU would be non-beneficial (futile), most refused patients are deprived of the potential benefits of ICU admission, even if these benefits may be small.

Part of the ethical and moral justification for triage requires that exhaustive efforts to maximise efficiency in healthcare systems to ensure that we achieve as much good as possible with the resources we already have, are necessary. ${ }^{[85]}$ Only once this is done, can rationing be justified. An approach to this question was developed in question 4

The process of triage should not be reliant on the solitary judgment of individuals, but be guided by institutional policies, and require some degree of peer-review, and validation from a broad spectrum of opinion. ${ }^{[86]}$ Thus, triage policies should be justified and defensible, respecting the moral contract between healthcare workers, patients and the wider public. Policy implementation therefore includes the need for openness and transparency, accountability, and provision of mechanisms of appeal and review by relevant stakeholders. ${ }^{[87]}$

The legal position of a medical decision to refuse ICU care on the basis of triage, especially in the face of patient or family demands for treatment, is unknown. However, the attitude of South African courts to the question of resource rationing and prioritisation may be inferred from a Supreme Court judgment in 1997. Briefly, the hospital concerned argued successfully that the patient who suffered from chronic kidney failure, and did not meet kidney transplant criteria, therefore had an incurable disease and should not be treated further, specifically as further treatment would deny treatment to other patients for whom a cure was possible. The patient, who later died, had argued that their right to life was guaranteed by the constitution. One of the trial judges further stated while an individual's need for access to public medical resources was entitled to individual consideration, decisions to deny access that were not regulated by the existence and application of 'principled criteria' could be more open to challenge. ${ }^{[88]}$

In conclusion, although several competing ethical and moral justifications may be used to guide a triage policy, the consensus group unanimously supported the principle of admission priority for patients likely to result in the greatest benefit for the greatest number of patients from available resources.

\section{Recommendation}

Triage decisions in SA should be made on the basis of achieving the greatest medical benefit from the available ICU resources (Ungraded).

Patients should be prioritised such that those with the greatest likelihood of incremental medical benefit from ICU admission are given priority for admission (Ungraded).

\subsection{Is there evidence to inform the best practice of admission, triage and rationing in $\mathrm{SA}$ ?}

The systematic literature search revealed no randomised controlled trials of routine triage interventions in an adult ICU population, few observational studies reporting practice and outcomes, ${ }^{[38-47,89]}$ and one systematic review of observational studies. ${ }^{[48]}$ Reported factors associated with triage decisions to decline admission include old age, greater severity of illness, poor chronic health status (particularly chronic respiratory and cardiac disease or lack of independence in activities of daily living), diagnostic category (metastatic neoplasm, post cardiac arrest, non-operative referrals), few ICU beds immediately available, and need for observation only. ${ }^{[43,45,90,91]}$

While these observational data are informative, there is sparse available evidence to inform best practice for admission, triage and rationing decisions. While international expert consensus guidelines have been published, they have been developed in highincome countries with substantial intensive care resources. ${ }^{[29,54,61]}$ The expert group recognises that in SA, the majority of centres perform triage in isolation, and few institutions have protocols and guidelines to inform practice. The expert group further recognises that the decision to admit a patient to ICU under conditions of resource limitation is inherently challenging because of scientific uncertainty, continuous advances in knowledge and technology, and our limited ability to accurately predict outcomes. The need for evidence-based prognostication as part of triage decision-making is addressed further in the response to question 9.

\section{Recommendation}

Further research, particularly in SA, is required to support the development of best practice guidelines for admission, triage and rationing, the goals of which should include minimising loss of life of critically ill patients, and maximal utilisation of limited resources within an ethical framework acceptable in SA (Ungraded). 


\subsection{Are scoring systems useful to guide or assist admission, triage and rationing decisions, particularly in SA?}

The availability of an objective, accurate, immediately assessable and easy-to-use score to predict incremental magnitude of benefit from ICU care and therefore guide admission, triage and rationing decisions, would clearly be desirable. Attempts to develop prognostic and triage scoring systems for routine use in resource-limited environments have been made. ${ }^{[46]}$

Increasingly, and in the wake of recent outbreaks of infectious respiratory diseases, several triage scoring systems for use in situations where ICU bed resources are acutely overwhelmed have been proposed. ${ }^{[92-94]}$ All triage scoring systems have been based on the general utilitarian principle of achieving maximum benefit (improved mortality) from available resources. Simulated utilisation of the scores has demonstrated that some have potential to inform triage decisions and potentially reduce ICU bed utilisation. ${ }^{[95,96]}$ Unfortunately, attempts to validate simulations against actual important outcomes such as mortality, have demonstrated relatively poor performance. ${ }^{[97-99]}$ This is possibly because of the inability of current scoring systems to replicate the complex nature of triage decisions. Key deficiencies include the measurement or prediction of outcome only of patients admitted to the ICU and neglect to make a direct comparison with the likely outcome if the patient remains in the general ward (or other current level of care), therefore overestimating potential benefit; the need for detailed clinical data that are not always available; the use of relatively short-term mortality as the only measurable outcome, ignoring important outcomes such as longer term outcome and quality of life; and lack of consideration of the resource use required to achieve the expected outcome. While providing reasonably accurate discrimination for groups of patients, a key technical deficiency of currently available severity scores is their relatively poor calibration, which prevents the accurate prediction of important outcomes in individual patients. ${ }^{[100]}$ While proposals for methods to improve triage-specific scoring systems have been made, ${ }^{[101]}$ currently proposed objective scores remain inadequate for stand-alone clinical use.

Nevertheless, despite the current inability of scoring systems to predict accurately in individual patients, or combine all aspects of triage decision-making into one instrument, it remains important that accurate, evidence-based prognostic scoring systems continue to be developed, calibrated and validated for use by clinicians to assist and inform triage decisions. Several such scores and prognostic tools exist, even if not specifically developed to inform triage decisions, and may be used by clinicians to improve the objectivity of assessments of prognosis when appropriate. Many such scores are relatively simple, do not require extensive laboratory testing, and can be completed in an acceptably short time to assist immediate decision-making. Examples include general mortality predictive scores such as the Mortality Probability Admission Model $\left.\left(\mathrm{MPM}_{0}\right)\right)^{[102]}$ a general hospital mortality prediction rule, ${ }^{[103]}$ and the National Early Warning score (NEWS). ${ }^{[104]}$ Other well-known scores such as the acute physiology and chronic health evaluation (APACHE II), simplified acute physiology score (SAPS II) and sequential organ failure assessment (SOFA) scores are complex, require laboratory testing, ${ }^{[105-107]}$ and may require up to 24 hours for scoring, ${ }^{[105]}$ therefore rendering them unsuitable to inform immediate triage decisions. The pneumonia severity index (PSI) also falls into this category; ${ }^{[108]}$ however, other relatively simple point-ofcare predictive scores for individual conditions of importance in SA include community-acquired pneumonia (the CURB-65 score and the IDSA/ATS minor criteria for ICU admission), ${ }^{[109,110]}$ traumatic intracranial haemorrhage clinical decision rules, ${ }^{[11,112]}$ and malaria outcome score. ${ }^{[113]}$ Such scores may be relatively easily accessed and used to inform and improve individual prognostication.

Assessment of prognosis in a rapidly ageing population is a new and increasing challenge. ${ }^{[114]}$ In the context of critical illness, the determination of frailty, rather than chronological age, appears more important for the purposes of prognostication. Frailty scores, particularly in the elderly, have been shown to predict mortality and quality of life outcomes better than age alone, independently of other traditional predictive scores. ${ }^{[115-118]}$ The systematic assessment of frailty as a prognostic indicator is likely to become increasingly important in the determination of prognosis in the setting of triage. ${ }^{[119]}$

Therefore, while scoring systems may assist and inform prognostication at the time of triage, at present prognostication by individual doctors remains the clinical standard. Studies have shown that doctors are capable of moderately good mortality prognostication, ${ }^{[120,121]}$ and that the accuracy of prognostication increases with the individual's confidence in making a particular prediction. ${ }^{[121]}$ When decisions were in concordance with those of other individuals, accuracy was markedly enhanced. ${ }^{[121]}$

It is important to remember that conditions of reduced incremental benefit from ICU admission may occur on both prognostic extremes. Patients may be too well for ICU care or they may be so ill that the chance of salvage is minimal. It is important to recognise that even if more accurate and discriminatory prognostic tools become available in the future, a value judgment would still be necessary to decide what would be the minimum difference in predicted incremental mortality benefit that would be morally justified ${ }^{[61]}$ For example, in conditions of severe resource limitations in parts of SA, it may be medically reasonable to reject a patient to the ICU with a $30 \%$ incremental risk of survival with ICU care (95\% risk of death without ICU care v. $65 \%$ risk of death with ICU admission), in favour of a patient with a greater likely incremental benefit. However, in high-income countries, such a risk of death differential would be unlikely to meet a threshold for refusal of care on the basis of triage. ${ }^{[59]}$ Therefore, thresholds for triage decision-making should be appropriate to local ICU resource availability in South Africa.

In conclusion, scoring systems have promise for the future but, under current conditions in SA, have inadequate precision for direct clinical use. The use of systematically collected data, and scoring systems to determine prognosis, are strongly encouraged.

\section{Recommendation}

No suitable, comprehensive and objective triage scoring system is currently suitable for use in SA (1C).

Although triage decisions currently remain a considered clinical judgment, the use of predictive scoring systems, including those measuring frailty, to improve the accuracy of clinical prognostication as part of triage decision-making is encouraged (1C). 
3.10. Are there specific issues in SA, e.g. availability of rehabilitation/chronic care facilities, or unequal access to such facilities, that the ICU specialist ought to consider when making ICU admission, triage and rationing decisions, that are different to general issues in other countries?

Facilities for supporting chronic ventilation, rehabilitation and chronic care are severely limited for the majority of the population. Consequently, patient-centred satisfactory outcomes, measured as length of survival or quality of life, for many patients in SA may be less frequent than for the equivalent situation in other middleincome or high-income countries. Thus, the evaluation of potential benefit from ICU care may need to be considered in the light of potential anticipated post-ICU support. It must, however, be recognised that access to post-ICU support may also be related to financial, ethnic and social factors and these may influence the fair allocation of available resources.

\section{Recommendation}

The lack of availability of social or medical support for rehabilitation post ICU admission should only be considered at the time of triage decision-making if their absence would materially and substantially prevent benefit being derived from ICU care (Ungraded).

Care must be taken to avoid discrimination on the basis of gender, race, religion, educational achievement or level of affluence (Ungraded).

\subsection{Should patients already in the ICU receive priority over patients queueing for admission?}

The use of a triage process in response to resource limitation occurs explicitly both internationally and in SA. ${ }^{[15,37-47,54]}$ It is increasingly clear that some patients already in the ICU fail to respond well to treatment and have a poor prognosis for recovery, with benefit likely to be small. Current international guidelines for end-oflife (EOL) care are based on actions taken in the patient's best interest. ${ }^{[122]}$ This is based on the principle that once patients are admitted, the intensivist has direct responsibility to the individual patient and therefore considerations of resource consumption and utilisation are subsequently ignored. As a consequence, these patients are rarely discharged to the ward to make way for a patient with a greater likelihood of benefit. Previously published triage guidelines and consensus documents have stated, 'As a general rule, obligations to patients already hospitalised in an ICU who continue to warrant ICU care outweigh obligations to accept new patients. ${ }^{[54,60,61]}$ In the more recent consensus document, however, that statement only received $77 \%$ agreement, falling short of the required $80 \%$ to make a firm recommendation. ${ }^{[59]}$ It has also been systematically argued that there are no clear and obvious ethical or moral reasons why patients already in the ICU should receive priority over patients queueing for admission. ${ }^{[123]}$ If this argument, that triage of potential new admissions and those already in the ICU is ethically and morally equivalent, then the possibility of discharging patients with limited chances of benefit from the ICU (potentially against the family or patient's wishes) to allow patients with a greater chance of benefit to be admitted, may be considered. In pandemic and disaster situations, it has been suggested by expert groups that if, after a suitable time period, a patient meets exclusion criteria for admission, consideration should be given to withdrawal of life support. ${ }^{[66]}$ It has been suggested that South African physicians prefer making triage decisions at the time of admission, rather than initiating a 'trial of therapy' following admission, during which an inadequate response to therapy is followed by early withdrawal of therapy. ${ }^{[124]}$

In conclusion, consensus as to how such actions could be justified and systematically implemented on a day-to-day basis in chronically resource-restricted countries such as SA could not be reached by our expert group, unless circumstances were clear and obvious, and that on balance the of loss of benefit from a patient undergoing ICU care was likely to be small, and the benefit from a new admission substantially higher. This approach is generally in line with statements from other expert groups and consensus statements. ${ }^{[59,61]}$

\section{Recommendation}

Patients already admitted to an ICU who continue to warrant ICU care should usually receive priority over new admissions. Exceptions are appropriate when, on balance, if discharged to a lower level of care, the of loss of incremental benefit from continued ICU care would probably be small, and the benefit for a new admission substantially higher (Ungraded).

\subsection{Is there a need that admission, triage and} rationing policies and guidelines in SA be transparently promulgated, periodically reviewed and/or audited by frontline healthcare workers, e.g. through professional organisations?

Admission, triage and rationing guidelines, and policies at individual hospitals and ICUs that may be developed from the recommendations, potentially affect a number of stakeholders. ICU admission and triage decisions are potentially life changing for individuals ${ }^{[48]}$ and their families ${ }^{[125]}$ and are therefore a serious matter. While the composition of the current expert group is broadbased in stakeholder representation, it is not comprehensive, and therefore any recommendations or guidelines must be transparently communicated to all potential stakeholders.

Processes for creating recommendations for decision-making with strong ethical and moral dimensions have been proposed. ${ }^{[87,126]}$ The recommended process includes several additional steps beyond inclusivity, transparency and communication, and includes publishing the grounds for recommendations and guidelines that gave rise to the decisions; recommendations should be relevant to stakeholders' views regarding the equitable distribution of specific health needs (in this case, rationing of ICU resources), and procedures must exist to allow revision of decisions in the light of challenges to them. ${ }^{[87,126]}$ This should take the form of an appeal process of which affected patients or their surrogate decision-makers are explicitly aware. ${ }^{[61,86]}$ All these aspects must be built into the guideline development process in individual hospitals and units. ${ }^{[36]}$

The resources and processes available for care of critically ill patients in hospitals and in intensive care have been shown to change over time, ${ }^{[127]}$ and also under conditions of stress (surge situations), ${ }^{[128,129]}$ which provides a rationale for the need for a 
recommended framework that is adaptable and scalable, and emphasises the need for regular review of the guidelines to ensure that they remain updated and appropriate.

It seems reasonable to expect that policies should be generated and proposed by healthcare workers (from both within and outside the ICU) as they have a detailed sense of the necessities of function in those areas. The advantage of using professional organisations to provide overall policies is that they are less likely to have vested interests in selected healthcare services in particular contexts. However, there should be complete transparency regarding the affiliations and potential conflicts of interests of the professionals involved.

It is intrinsically difficult to establish the views and preferences of the target population and, probably for this reason, previously published international guidelines have failed to directly identify or consider patient views or preferences relating to routine ICU admission triage. The lack of substantial direct participation of the lay public in expressing their views and preferences is a limitation that is acknowledged; however, this limitation was partially addressed by including a non-medical lawyer and an ethicist as a participant member. In addition, the literature review identified a small number of studies that have addressed the general public's view on ICU admission triage decisions in the context of pandemics. ${ }^{[130-132]}$ These surveys report substantial public support for triage decisions being made in universal access public healthcare systems in the face of overwhelmed resources, that these decisions be made by senior doctors supported by pre-determined and transparent guidelines, ${ }^{[131,132]}$ and that they are fairly applied to all. ${ }^{[130,131]}$ Public views were thus determined to be aligned, as far as can currently be ascertained, with the views of the participating medical members of the consensus group. The triage framework tool, developed as part of this consensus meeting, was designed as far as possible to meet these public expectations.

The actual implementation of policies is challenging even within single units and it is expected, when resources allow, that implementation should be accompanied by the collection of appropriate data to provide audit information on the quality of policy implementation. An extensive list of audit information that should be collected to allow quality assurance and service improvement in the domain of ICU triage has been published recently. ${ }^{[29]}$ However, participants recognised that severely restricted manpower and other resources precludes the prescription of such detailed metrics in the South African setting. Nevertheless, even in the South African setting, attempts to record as much data as practical is encouraged. Some key audit metrics that should be recorded whenever practicable are summarised in Table 3 .

Additional to these ethical and moral requirements, the publication of guidelines without efforts to promote implementation through active distribution of information, educational initiatives, and efforts to measure implementation and effect, is at best moderate. ${ }^{[68]}$

\section{Recommendation}

Any admission, triage and rationing policies and guidelines in SA should be transparently promulgated by professional bodies, and be freely and conveniently available to all stakeholders, including the public (Ungraded).
These policies and guidelines should be periodically reviewed and/ or audited (Ungraded).

\subsection{Should more research in the subject area of ICU admission, triage and rationing decisions be prioritised?} A systematic search for published articles in the subject area revealed a preponderance of scholarly articles describing ethical and moral arguments, consensus reports and guidelines on best practice. Several papers described the practice of triage in specific cohorts of patients; however, few addressed the consequences of triage, and none used robust methodology to assess the impact of specific triage-related interventions on meaningful patient outcomes. Overall it is clear that more research, focused specifically on triage and rationing in the presence of chronic resource limitation, is necessary. This is especially true for the South African environment, where ICU resource limitations are pervasive in the public sector, and only a minority of patients have access to the parallel, but relatively resource-rich, private health system.

The group identified key areas of research required to promote both efficiency of resource use and best implementation of triage. These include ICU practice quality monitoring and improvement, critical illness prognoses, and scoring systems for triage and triage outcomes. In particular, decisions to admit or not are challenging because of uncertainty regarding prognoses, which are in any case continually changing as a result of advances in knowledge and technology. Consequently, our ability to predict outcomes accurately remains limited despite ongoing research efforts. ${ }^{[133]}$ The current lack of accurate outcome information, especially in SA, that would facilitate such judgments, complicates decision-making. Simple questions such as which potential ICU patients would do just as well with care in an intermediate unit, are difficult to answer with current knowledge. ${ }^{[58,61]}$ Additionally, post ICU and hospital life expectancy, and functional status, is essential information in order to weigh the benefits and cost of ICU admission. Long-term societal costs associated with poor outcomes should also be available in order to assess properly whether ICU care might be too costly relative to benefit. Although there are some data to predict the outcomes following ICU admission, little data exist on which to base predictions as to what would occur without intensive care admission. If scoring systems become available, they should estimate incremental benefit. It remains necessary to compare predictions based on scoring systems robustly with clinical judgment as to prognosis. When adopting the utilitarian approach to triage, it is necessary to determine both incremental cost and benefit. For the purposes of triage, cost is most easily estimated by predicted ICU length of stay, another parameter for which there are sparse predictive data. ${ }^{[61,100]}$

\section{Recommendation}

There is an urgent need for research to improve efficiency of ICU services in SA and to inform the practice of triage, particularly in the following domains (1C).

- Descriptive data - rates of referral, refusal rate, reasons for refusal, and outcomes (survival, functional status and quality of life, including likely duration of such outcomes)

- Research assessing the impact of recommendations and guidelines - audit of implementation and the impact of guidelines on practice 
- Prognosis of critically ill patients referred to ICU, documenting outcomes of those patients admitted and refused, or offered alternative levels of care

- Development of prognostic scoring systems with high discrimination and calibration for critically ill patients, adjusted for level of care (e.g. with ICU, high-dependancy unit or ward care).

\subsection{Should any proposed ICU admission, triage and rationing guidelines and policies also address discharge criteria?}

The efficient use of available ICU resources requires that patients who no longer benefit from ongoing ICU care are discharged to a lower level of care appropriate to their needs. Under normal circumstances, this occurs when patients have recovered sufficiently to be transferred safely to a step-down high-dependency unit, if available, or general wards. Some selected patients may be best cared for in a special care unit, such as a chronic ventilator unit or units specialising in certain kinds of rehabilitation such as a spinal care unit. Clinicians in the ICU should be alert to the recognition of patients who may be ready for discharge to an appropriate lower level of care, so that delays in discharge are minimised. Therefore discharge should be based on an ongoing evaluation of the likelihood of recovery and whether or not it is safe to discharge.

Formal early-discharge planning interventions may improve readiness for discharge in selected patients. ${ }^{[134]}$ It must be remembered that premature discharge may lead to deterioration in the patient's condition and result in re-admission or a potentially preventable death. ${ }^{[135-137]}$ Factors associated with re-admission or death post discharge have been identified and include central nervous system dysfunction, severity of organ failure during admission, and the number of comorbidities. ${ }^{[136,138-143]}$ Clinicians should be aware of these data when making discharge decisions, particularly as pressure for beds may affect decision-making, resulting in patients who are marginally stable and not yet fully safe being discharged to general wards. ${ }^{[135,144]}$

Algorithms and scoring systems to assist identification of patients suitable for safe discharge have been proposed and may be considered to assist discharge decision-making; ${ }^{[145,146]}$ however, none has been adequately validated in independent patient cohorts.

The expert group considered other circumstances that may warrant discharge when resource restrictions create pressure to mobilise ICU beds to accommodate potential patients who have a substantial expected benefit. Discharge from ICU may be considered when a decision to withdraw life support has been made, and such practice has previously been reported. ${ }^{[140]}$ Such discharges should only be implemented provided that the resulting medical and nursing care will be sufficient to ensure control of pain or suffering, the predicted ICU bed time that would be made available by early discharge is substantial, and the degree of need by another patient for the ICU bed is high. ${ }^{[61]}$ Similar considerations may be made for patients in the ICU who no longer have the prospect of gaining substantial benefit from ongoing ICU care.

In the South African setting, it was considered desirable to develop and utilise step-down, high-dependency units to manage patients with slowly responding conditions, in whom all the services of an acute ICU were not required. For example, such units could manage haemodynamically stable, tracheostomised and spontaneously breathing patients, who may be at risk of sputum retention or inadvertent extubation in a general ward.

Written guidelines, policies or criteria for discharge of patients from ICUs are uncommon and, even when available, appear to be infrequently implemented. ${ }^{[147,148]}$ The expert group confirmed similar practice variation was present in South African ICUs.

In conclusion, the availability and use of guidelines to optimise bed use in constrained circumstances is likely to improve the efficiency of available ICU beds. Those responsible for discharge decisions, namely intensivists, should take on the responsibility of developing such guidelines to ensure as far as possible the safety of those who are discharged.

\section{Recommendation}

Intensive care specialists should take on the responsibility of developing guidelines to ensure as far as possible the safety of those who are discharged. (Ungraded)

\section{Conclusion}

In the context of the need to limit the access of some patients to ICU because of lack of intensive care resources in public hospitals, these recommendations were developed to improve patient care, and guide policy-making in SA. While several of the consensus group were chosen for their clinical expertise and experience in triage and the practice of intensive care in resource-limited environments, a limitation of the statement was the lack of additional external expert review during the development process. Nevertheless, we believe the statement substantially reflects current available evidence and a responsible body of expert opinion in SA. While there will inevitably be situations where decision-making may be individualised for justifiable reasons, these recommendations and the accompanying guideline are intended to be a tool to guide current and future best practice for admission, triage and rationing. The recommendations and the accompanying guideline should not be considered a complete plan for quality practice, but rather the beginning of a long-term strategic initiative to engage clinicians, the public and administrators in appropriate triage decision-making, as well as to promote audit and research that will lead to systems enhancement that will ultimately maximise the fair use of ICU resources.

1. Marshall JC, Bosco L, Adhikari NK, et al. What is an intensive care unit? A report of the task force of the World Federation of Societies of Intensive and Critical Care Medicine. J Crit Care 2017;37:270-276. https://doi.org/10.1016/j.jcrc.2016.07.015

2. Fowler RA, Adhikari NK, Bhagwanjee S. Clinical review: Critical care in the global context disparities in burden of illness, access, and economics. Critical Care 2008;12(5):225. https:// doi.org/10.1186/cc6984

3. Murthy S, Wunsch H. Clinical review: International comparisons in critical care - lessons learned. Critical Care 2012;16(2):218. https://doi.org/10.1186/cc11140

4. Prin M, Wunsch H. International comparisons of intensive care: Informing outcomes and improving standards. Curr Opin Crit Care 2012;18(6):700-706. https://doi.org/10.1097/ MCC.0b013e32835914d

5. Scheunemann LP, White DB. The ethics and reality of rationing in medicine. Chest 2011;140(6):1625-1632. https://doi.org/10.1378/chest.11-0622

6. Bassford C. Decisions regarding admission to the ICU and international initiatives to improve the decision-making process. Critical Care 2017;21(1):174. https://doi.org/10.1186/ s13054-017-1749-3

7. Joynt GM, Gopalan PD, Argent A, et al. The Critical Care Society of Southern Africa Consensus Guideline on ICU Triage and Rationing (ConICTri). S Afr Med J 2019;109(8):630642. https://doi.org/10.7196.SAMJ.v109i8.13947

8. Brouwers MC, Kho ME, Browman GP, et al. AGREE II: Advancing guideline development, reporting and evaluation in healthcare. CMAJ 2010;182(18):E839-E842. https://doi. org/10.1503/cmaj.090449

9. Iserson KV, Moskop JC. Triage in medicine, Part I: Concept, history, and types. Ann Emerg Med 2007;49(3):275-281. https://doi.org/10.1016/j.annemergmed.2006.05.019

10. Pill J. The Delphi method: Substance, context, a critique and an annotated bibliography. Socioecon Plann Sci 1971;5(1):57-71. https://doi.org/10.1016/0038-0121(71)90041-3 
11. Neumann I, Santesso N, Akl EA, et al. A guide for health professionals to interpret and use recommendations in guidelines developed with the GRADE approach. J Clin Epidemiol 2016;72:45-55. https://doi.org/10.1016/j.jclinepi.2015.11.017

12. Guyatt GH, Oxman AD, Vist GE, et al. GRADE: An emerging consensus on rating qualit of evidence and strength of recommendations. BMJ 2008;336(7650):924-926. https://do org/10.1136/bmj.39489.470347.AD

13. Qaseem A, Snow V, Owens DK, Shekelle P. Clinical Guidelines Committee of the American College of Physicians. The Development of Clinical Practice Guidelines and Guidance Statements of the American College of Physicians: Summary of methods. Ann Intern Med 2010;153(3):194-199. https://doi.org/10.7326/0003-4819-153-3-201008030-00010

14. Statistics South Africa. Mid-year population estimates 2016. Pretoria: StatsSA; 2016. http:// www.statssa.gov.za/publications/P0302/P03022016.pdf (accessed 1 February 2018).

15. Burch VC, Benatar SR. Rational planning for health care based on observed needs. S Afr Med J 2006;96(9):796-802.

16. van Zyl-Smit R, Burch V, Willcox $P$. The need for appropriate critical care service provision at non-tertiary hospitals in South Africa. S Afr Med J 2007;97(4):268-272.

17. Skinner DL, De Vasconcellos K, Wise R, et al. Critical care admission of South African (SA) surgical patients: Results of the SA Surgical Outcomes Study. S Afr Med J 2017;107(5):411 419. https://doi.org/10.7196/SAMJ.2017.v107i5.11455

18. Scribante J, Bhagwanjee S. National audit of critical care resources in South Africa - research methodology. S Afr Med J 2007;97(12 Pt 3):1308-1310.

19. Bhagwanjee S, Scribante J. National audit of critical care resources in South Africa - unit and bed distribution. S Afr Med J 2007;97(12 Pt 3):1311-1314.

20. Naidoo K, Singh J, Lalloo U. Critical analysis of ICU/HC beds in South Africa: 2008-2009. S Afr Med J 2013;103(10):751-753.

21. Scribante J, Bhagwanjee S. National audit of critical care resources in South Africa-open versus closed intensive and high care units. SAfr Med J 2007;97(12):1319-1322.

22. Scribante J, Bhagwanjee S. National audit of critical care resources in South Africa-nursing profile. S Afr Med J 2007;97(12):1315-1318.

23. Core Standards Working Party of the Joint Professional Standards Committee, Professiona Standards Committee of the Faculty of Intensive Care Medicine and the Standards, Safety and Quality Committee of the Intensive Care Society. Core Standards for Intensive Care Units. 2013. https://www.ficm.ac.uk/sites/default/files/Core\%20Standards $\% 20$ for $\% 20$ ICUs\%20Ed.1\%20(2013).pdf (accessed 3 January 2019).

24. Chamberlain D, Pollock W, Fulbrook P. ACCCN Workforce Standards for Intensive Care Nursing: Systematic and evidence review, development, and appraisal. Aust Crit Care 2018;31(5):292-302. https://doi.org/10.1016/j.aucc.2017.08.007

25. Tarnow-Mordi WO, Hau C, Warden A, Shearer AJ. Hospital mortality in relation to staff workload: A 4-year study in an adult intensive-care unit. Lancet 2000;356(9225):185-189.

26. West E, Barron DN, Harrison D, et al. Nurse staffing, medical staffing and mortality in intensive care: An observational study. Int J Nurs Stud 2014;51(5):781-794. https://doi. org/10.1016/j.jinurstu.2014.02.007

27. Sakr Y, Moreira CL, Rhodes A, et al. The impact of hospital and ICU organizational factors on outcome in critically ill patients: Results from the Extended Prevalence of Infection in Intensive Care study. Crit Care Med 2015;43(3):519-526. https://doi.org/10.1097/ $\mathrm{ccm} .0000000000000754$

28. Lee A, Cheung YSL, Joynt GM, et al. Are high nurse workload/staffing ratios associated with decreased survival in critically ill patients? A cohort study. Ann Intensive Care 2017;7(1):46. https://doi.org/10.1186/s13613-017-0269-2

29. Nates JL, Nunnally M, Kleinpell R, et al. ICU admission, discharge, and triage guidelines: A framework to enhance clinical operations, development of institutional policies, A framework to enhance clinical operations, development of institutional policies,
and further research. Crit Care Med 2016;44(8):1553-1602. https://doi.org/10.1097/ and further research.

30. Wallace DJ, Angus DC, Barnato AE, Kramer AA, Kahn JM. Nighttime intensivist staffing and mortality among critically ill patients. N Engl J Med 2012;366(22):2093-2101. https:// doi.org/10.1056/NEJMsa1201918

31. Wilcox ME, Chong CA, Niven DJ, et al. Do intensivist staffing patterns influence hospital mortality following ICU admission? A systematic review and meta-analyses. Crit Care Med 2013;41(10):2253-2274. https://doi.org/10.1097/CCM.0b013e318292313

32. Checkley W, Martin GS, Brown SM, et al. Structure, process, and annual ICU mortality across 69 centers: United States Critical Illness and Injury Trials Group Critical Illness Outcomes Study. Crit Care Med 2014;42(2):344-356. https://doi.org/10.1097/CCM.0b013e3182a275d7

33. Burrows R. Removal of life support in intensive care units. Med Law 1994;13(5-6):489-500.

34. Gopalan P, Bhagwanjee S, Burrows R. Referral patterns of two intensive care units in the greater Durban area. S Afr Med J 1998;88(11):1452.

35. Hurri H. Profile of ICU bed requests at Helen Joseph hospital (MMed degree). Johannesburg: University of the Witwatersrand; 2015.

36. Argent AC, Ahrens J, Morrow BM, et al. Pediatric intensive care in South Africa: An account of making optimum use of limited resources at the Red Cross War Memoria Children's Hospital. Pediatr Crit Care Med 2014;15(1):7-14. https://doi.org/10.1097/ pcc.0000000000000029

37. Gordon K, Allorto N, Wise R. Analysis of referrals and triage patterns in a South African metropolitan adult intensive care service. S Afr Med J 2015;105(6):491-495.

38. Marshall MF, Schwenzer KJ, Orsina M, Fletcher JC, Durbin CGJ. Influence of political power, medical provincialism, and economic incentives on the rationing of surgical intensive care unit beds. Crit Care Med 1992;20(3):387-394

39. Frisho-Lima P, Gurman G, Schapira A, Porath A. Rationing critical care -- what happens to patients who are not admitted? Theor Surg 1994;9(4):208-211.

40. Metcalfe MA, Sloggett A, McPherson K. Mortality among appropriately referred patients refused admission to intensive-care units. Lancet 1997;350(9070):7-11. https://doi. org/10.1016/s0140-6736(96)10018-0

41. Sprung CL, Geber D, Eidelman LA, et al. Evaluation of triage decisions for intensive care admission. Crit Care Med 1999;27(6):1073-1079.

42. Azoulay E, Pochard F, Chevret S, et al. Compliance with triage to intensive care recommendations. Crit Care Med 2001;29(11):2132-2136.

43. Joynt GM, Gomersall CD, Tan P, et al. Prospective evaluation of patients refused admission to an intensive care unit: triage, futility and outcome. Intensive Care Med 2001;27(9):14591465. https://doi.org/10.1007/s00134010104

44. Shum HP, Chan KC, Lau CW, et al. Triage decisions and outcomes for patients with Triage Priority 3 on the Society of Critical Care Medicine scale. Crit Care Resus 2010;12(1):42-49.
45. Iapichino G, Corbella D, Minelli C, et al. Reasons for refusal of admission to intensive care and impact on mortality. Intensive Care Med 2010;36(10):1772-1779. https://doi. care and impact on mortality.
org $/ 10.1007 /$ s00134-010-1933-2

46. Sprung CL, Baras M, Iapichino G, et al. The Eldicus prospective, observational study of triage decision making in European intensive care units: Part I--European Intensive Care Admission Triage Scores. Crit Care Med 2012;40(1):125-131. https://doi.org/10.1097/ CCM.0b013e31822e5692

47. Andersen FH, Flaatten H, Klepstad P, et al. Long-term outcomes after ICU admission triage in octogenarians. Crit Care Med 2017;45(4):e363-e371. https://doi.org/10.1097/ ccm.0000000000002098

48. Sinuff T, Kahnamoui K, Cook DJ, Luce JM, Levy MM. Rationing critical care beds: A systematic review. Crit Care Med 2004;32(7):1588-1597.

49. Cardoso LT, Grion CM, Matsuo T, et al. Impact of delayed admission to intensive care units on mortality of critically ill patients: A cohort study. Crit Care 2011;15(1):R28. https://doi org/10.1186/cc9975

50. Robert R, Reignier J, Tournoux-Facon C, et al. Refusal of intensive care unit admission due to a full unit: Impact on mortality. Am J Respir Crit Care Med 2012;185(10):1081-1087. https://doi.org/10.1164/rccm.201104-0729OC

51. Naser W, Schwartz N, Finkelstein R, Bisharat N. Outcome of mechanically ventilated patients initially denied admission to an intensive care unit and subsequently admitted. Eur J Intern Med 2016;35:100-105. https://doi.org/10.1016/j.ejim.2016.05.006

52. Hersch M, Sonnenblick M, Karlic A, et al. Mechanical ventilation of patients hospitalized in medical wards vs the intensive care unit--an observational, comparative study. J Crit Care 2007;22(1):13-17. https://doi.org/10.1016/j.jcrc.2006.06.004

53. Tang WM, Tong CK, Yu WC, Tong KL, Buckley TA. Outcome of adult critically ill patient mechanically ventilated on general medical wards. Hong Kong Med J 2012;18(4):284-290.

54. Consensus statement on the triage of critically ill patients. Society of Critical Care Medicine Ethics Committee. JAMA 1994:271(15):1200-1203.

55. Hersch M, Izbicki G, Dahan D, et al. Predictors of mortality of mechanically ventilated patients in internal medicine wards. J Crit Care 2012;27(6):694-701. https://doi. org/10.1016/j.jcrc.2012.08.020

56. Parker K, Perikala V, Aminazad A, et al. Models of care for non-invasive ventilation in the Acute COPD Comparison of three Tertiary hospitals (ACT3) study. Respirology 2018;23(5):492-497. https://doi.org/10.1111/resp.13228

57. McIlroy DR, Coleman BD, Myles PS. Outcomes following a shortage of high dependency unit beds for surgical patients. Anaesth Intensive Care 2006:34(4):457-463.

58. Joynt GM, Gomersall CD. Is 'more' always 'better'? Moving towards optimal utilization an of high dependency and intensive care beds by selecting the right patients for admission. Anaesth Intensive Care 2006;34(4):423-425.

59. Sprung CL, Danis M, Iapichino G, et al. Triage of intensive care patients: Identifying agreement and controversy. Intensive Care Med 2013;39(11):1916-1924. https://doi. org/10.1007/s00134-013-3033-6

60. Lumb P. The Durban declaration. J Crit Care 2013;28(6):887-889. https://doi.org/10.1016/j. jcrc.2013.10.001

61. Lanken PN, Terry PB, Adler DC, et al. Fair allocation of intensive care unit resources. Am J Respir Crit Care Med 1997;156(4):1282-1301. https://doi.org/10.1164/ajrccm.156.4.ats7-97

62. Walter KL, Siegler M, Hall JB. How decisions are made to admit patients to medica intensive care units (MICUs): A survey of MICU directors at academic medical centers across the United States. Crit Care Med 2008;36(2):414-420. https://doi.org/10.1097/01. Ccm.0000299738.26888.37

63. Blanch L, Abillama FF, Amin P, et al. Triage decisions for ICU admission: Report from the Task Force of the World Federation of Societies of Intensive and Critical Care Medicine. J Crit Care 2016;36:301-305. https://doi.org/10.1016/j.jcrc.2016.06.014

64. Sprung CL, Zimmerman JL, Christian MD, et al. Recommendations for intensive care unit and hospital preparations for an influenza epidemic or mass disaster: Summary report of the European Society of Intensive Care Medicine's Task Force for intensive care unit triage during an influenza epidemic or mass disaster. Intensive Care Med 2010;36(3):428-443. https://doi.org/10.1007/s00134-010-1759-y

65. Christian MD, Joynt GM, Hick JL, et al. Chapter 7. Critical care triage. Intensive Care Med 2010;36(Suppl 1):S55-S64. https://doi.org/10.1007/s00134-010-1765-0

66. Christian MD, Sprung CL, King MA, et al. Triage: Care of the critically ill and injured during pandemics and disasters: CHEST Consensus Statement. Chest 2014;146(4):e61Se74S. https://doi.org/10.1378/chest.14-0736

67. Hofmeyr R. South Africa: Where Are We Going? In: Crippen DW, ed. ICU Resource allocation in the new millennium: Will we say 'No'?. New York: Springer-Verlag; 2013:169-176.

68. Farmer AP, Legare F, Turcot L, et al. Printed educational materials: Effects on professiona practice and health care outcomes. Cochrane Database Syst Rev 2008(3):Cd004398. https://doi.org/10.1002/14651858.CD004398.pub2

69. Kredo T, Bernhardsson S, Machingaidze S, et al. Guide to clinical practice guidelines: The current state of play. Int J Qual Health Care 2016;28(1):122-128. https://doi.org/10.1093/ intqhe/mzv115

70. Clarke M, Loudon K. Effects on patients of their healthcare practitioner's or institution's participation in clinical trials: A systematic review. Trials 2011;12:16. https://doi.org/10.1186/1745 6215-12-16

71. Rochon J, du Bois A, Lange T. Mediation analysis of the relationship between institutional research activity and patient survival. BMC Med Res Methodol 2014;14:9. https://doi. org/10.1186/1471-2288-14-9

72. Gomberg-Maitland M, Murphy SA, Moliterno DJ, Cannon CP. Are we appropriately triaging patients with unstable angina? Am Heart J 2005;149(4):613-618. https://doi.org/10.1016/j. ahj.2004.09.035

73. Ramos JG, Perondi B, Dias RD, et al. Development of an algorithm to aid triage decisions for intensive care unit admission: A clinical vignette and retrospective cohort study. Crit Care 2016;20:81. https://doi.org/10.1186/s13054-016-1262-0

74. Katz DA, Griffith JL, Beshansky JR, Selker HP. The use of empiric clinical data in the evaluation of practice guidelines for unstable angina. JAMA 1996;276(19):1568-1574.

75. Hadorn DC. Who really needs to be in the intensive care unit: Using clinical guidelines to define healthcare needs. Crit Care Med 1994;22(10):1679-1682.

76. Carter JE, Neff LP, Holmes JH 4th. Adherence to burn center referral criteria: Are patients appropriately being referred? J Burn Care Res 2010;31(1):26-30. https://doi.org/10.1097/
BCR.0b013e3181cb8efb

77. Nesibopho and the Critical Care Society of Southern Africa. Best practice guidelines: nesibopho/showguidelines.pl (accessed 3 January 2019). 
78. Dougherty CJ. Ethical values at stake in health care reform. JAMA 1992;268(17):2409-2412. 79. Moskop JC, Iserson KV. Triage in medicine, part II: Underlying values and principles. Ann Emerg Med 2007;49(3):282-287. https://doi.org/10.1016/j.annemergmed.2006.07.012

80. Beauchamp TL, Childress JF. Moral Principles. Principles of Biomedical Ethics. New York: Oxford University Press, 2013.

81. Taurek JM. Should the numbers count? Philosophy \& Public Affairs 1977;6(4):293-316

82. Daniels N, Sabin JE. Setting limits fairly: Learning to share resources for health: New York: Oxford University Press; 2008.

83. Schneiderman LJ, Jecker NS, Jonsen AR. Medical futility: Its meaning and ethical implications. Ann Intern Med 1990;112(12):949-954

84. Bosslet GT, Pope TM, Rubenfeld GD, et al. An Official ATS/AACN/ACCP/ESICM/ SCCM Policy Statement: Responding to requests for potentially inappropriate treatments in intensive care units. Am J Respir Crit Care Med 2015;191(11):1318-1330. https://doi. in intensive care units. Am J Res
org/10.1164/rccm.201505-0924ST

85. Daniels N. Resource allocation and priority setting. In: Barrett DH, Ortmann LH, Dawson A, Saenz C, Reis A, Bolan G, eds. Public Health Ethics: Cases Spanning the Globe. Cham: Springer International Publishing, 2016: 61-94.

86. Tomlinson T, Czlonka D. Futility and hospital policy. Hastings Cent Rep 1995;25(3):28-35.

87. Daniels N. Accountability for reasonableness. BMJ 2000;321(7272):1300-1301.

88. Soobramoney v Minister of Health, KwaZulu-Natal 1998 (1) SA 765 (CC)

89. Simchen E, Sprung CL, Galai N, et al. Survival of critically ill patients hospitalized in and out of intensive care. Crit Care Med 2007;35(2):449-457. https://doi.org/10.1097/01. Ccm.0000253407.89594.15

90. Garrouste-Orgeas M, Boumendil A, Pateron D, et al. Selection of intensive care unit admission criteria for patients aged 80 years and over and compliance of emergency and intensive care unit physicians with the selected criteria: An observational, multicenter, intensive care unit physicians with the selected criteri
prospective study. Crit Care Med 2009;37(11):2919-2928.

91. Sprung CL, Artigas A, Kesecioglu J, et al. The Eldicus prospective, observational study of triage decision making in European intensive care units. Part II: Intensive care benefit for the elderly. Crit Care Med 2012;40(1):132-138. https://doi.org/10.1097/CCM.0b013e318232d6b0

92. Christian MD, Hawryluck L, Wax RS, et al. Development of a triage protocol for critical care during an influenza pandemic. CMAJ 2006;175(11):1377-1381. https://doi.org/10.1503/
cmaj.060911

93. Talmor D, Jones AE, Rubinson L, Howell MD, Shapiro NI. Simple triage scoring system predicting death and the need for critical care resources for use during epidemics. Crit Care predicting death and the need for critical care resources for use during epidemics.
Med 2007;35(5):1251-1256. https://doi.org/10.1097/01.Ccm.0000262385.95721.Cc

94. Cheung W, Myburgh J, Seppelt IM, et al. Development and evaluation of an influenza pandemic intensive care unit triage protocol. Crit Care Resusc 2012;14(3):185-190

95. Adeniji KA, Cusack R. The simple triage scoring system (STSS) successfully predicts mortality and critical care resource utilization in H1N1 pandemic flu: A retrospective analysis. Crit Care 2011;15(1):R39. https://doi.org/10.1186/cc10001

96. Cheung WK, Myburgh J, Seppelt IM, et al. A multicentre evaluation of two intensive care unit triage protocols for use in an influenza pandemic. Med J Aust 2012;197(3):178-181

97. Guest T, Tantam G, Donlin N, et al. An observational cohort study of triage for critical care
provision during pandemic influenza: 'clipboard physicians' or 'evidenced based medicine'? Anaesthesia 2009;64(11):1199-1206. https://doi.org/10.1111/j.1365-2044.2009.06084.x

98. Khan Z, Hulme J, Sherwood N. An assessment of the validity of SOFA score based triage in H1N1 critically ill patients during an influenza pandemic. Anaesthesia 2009;64(12):12831288. https://doi.org/10.1111/j.1365-2044.2009.06135.x

99. Shahpori R, Stelfox HT, Doig CJ, Boiteau PJ, Zygun DA. Sequential organ failure assessment in H1N1 pandemic planning. Crit Care Med 2011;39(4):827-832. https://doi.org/10.1097/ CCM.0b013e318206d548

100. Gomersall CD, Joynt GM. What is the benefit in triage? Crit Care Med 2011;39(4):911-912. https://doi.org/10.1097/CCM.0b013e31820b7415

101. Christian MD, Fowler R, Muller MP, et al. Critical care resource allocation: Trying to PREEDICCT outcomes without a crystal ball. Crit Care 2013;17(1):107. https://doi. PREEDICCT Outco
$\mathrm{org} / 10.1186 / \mathrm{cc} 11842$

102. Higgins TL, Teres D, Copes WS, et al. Assessing contemporary intensive care unit outcome: An updated Mortality Probability Admission Model (MPM0-III). Crit Care Med 2007;35(3):827-835. https://doi.org/10.1097/01.Ccm.0000257337.63529.9f

103. Cowen ME, Czerwinski JL, Posa PJ, et al. Implementation of a mortality prediction rule for real-time decision making: feasibility and validity. J Hosp Med 2014;9(11):720-726. https:// doi.org/10.1002/jhm. 2250

104. Bilben B, Grandal L, Sovik S. National Early Warning Score (NEWS) as an emergency department predictor of disease severity and 90 -day survival in the acutely dyspneic patient - a prospective observational study. Scand J Trauma Resusc Emerg Med 2016;24:80. https:// doi.org/10.1186/s13049-016-0273-9

105. Knaus WA, Draper EA, Wagner DP, Zimmerman JE. APACHE II: A severity of disease classification system. Crit Care Med 1985;13(10):818-829.

106. Le Gall JR, Lemeshow S, Saulnier F. A new Simplified Acute Physiology Score (SAPS II) based on a European/North American multicenter study. JAMA 1993;270(24):2957-2963.

107. Vincent JL, Moreno R, Takala J, et al. The SOFA (Sepsis-related Organ Failure Assessment) score to describe organ dysfunction/failure. On behalf of the Working Group on SepsisRelated Problems of the European Society of Intensive Care Medicine. Intensive Care Med 1996;22(7):707-710

108. Fine MJ, Auble TE, Yealy DM, et al. A prediction rule to identify low-risk patients with community-acquired pneumonia. N Engl J Med 1997;336(4):243-250. https://doi. org/10.1056/nejm199701233360402

109. Lim WS, van der Eerden MM, Laing R, et al. Defining community acquired pneumonia severity on presentation to hospital: An international derivation and validation study. Thorax 2003;58(5):377-382.

110. Chalmers JD, Taylor JK, Mandal P, et al. Validation of the Infectious Diseases Society of America/American Thoracic Society Minor Criteria for Intensive Care Unit Admission in Community-Acquired Pneumonia Patients Without Major Criteria or Contraindications to Intensive Care Unit Care. Clin Infect Dis 2011;53(6):503-511. https://doi.org/10.1093/ $\mathrm{cid} / \mathrm{cir} 463$

111. Nishijima DK, Shahlaie K, Echeverri A, Holmes JF. A clinical decision rule to predict adult patients with traumatic intracranial haemorrhage who do not require intensive care unit patients with traumatic intracranial haemorrhage who do not require intensive care
admission. Injury 2012;43(11):1827-1832. https://doi.org/10.1016/j.injury.2011.07.020
112. Eslami V, Saadat S, Rahimi-Movaghar V. A clinical decision rule to predict adult patients with traumatic intracranial haemorrhage who do not require intensive care unit admission. Injury 2013;44(11):1655-1656. https://doi.org/10.1016/j.injury.2012.11.019

113. Hanson J, Lee SJ, Mohanty S, et al. A simple score to predict the outcome of severe malaria in adults. Clin Infect Dis 2010;50(5):679-685. https://doi.org/10.1086/649928

114. Rockwood K, Song X, MacKnight C, et al. A global clinical measure of fitness and frailty in elderly people. CMAJ 2005;173(5):489-495. https://doi.org/10.1503/cmaj.050051

115. Bagshaw SM, Stelfox HT, McDermid RC, et al. Association between frailty and short- and long-term outcomes among critically ill patients: A multicentre prospective cohort study. CMAJ 2014;186(2):E95-E102. https://doi.org/10.1503/cmaj.130639

116. Bagshaw SM, Stelfox HT, Johnson JA, et al. Long-term association between frailty and healthrelated quality of life among survivors of critical illness: A prospective multicenter cohort study. Crit Care Med 2015;43(5):973-982. https://doi.org/10.1097/ccm.0000000000000860

117. Heyland DK, Garland A, Bagshaw SM, et al. Recovery after critical illness in patients aged 80 years or older: A multi-center prospective observational cohort study. Intensive Care Med 2015;41(11):1911-1920. https://doi.org/10.1007/s00134-015-4028-2

118. Brummel NE, Bell SP, Girard TD, et al. Frailty and subsequent disability and mortality among patients with critical illness. Am J Respir Crit Care Med 2017;196(1):64-72. https://doi. org/10.1164/rccm.201605-0939OC

119. Flaatten H, de Lange DW, Artigas A, et al. The status of intensive care medicine research and a future agenda for very old patients in the ICU. Intensive Care Med 2017;43(9):1319-1328. https://doi.org/10.1007/s00134-017-4718-z

120. Sinuff T, Adhikari NK, Cook DJ, et al. Mortality predictions in the intensive care unit: Comparing physicians with scoring systems. Crit Care Med 2006;34(3):878-885. https://doi. org/10.1097/01.Ccm.0000201881.58644.41

121. Detsky ME, Harhay MO, Bayard DF, et al. Discriminative accuracy of physician and nurse predictions for survival and functional outcomes 6 months after an ICU admission. JAMA 2017;317(21):2187-2195. https://doi.org/10.1001/jama.2017.4078

122. Sprung CL, Truog RD, Curtis JR, et al. Seeking worldwide professional consensus on the principles of end-of-life care for the critically ill. The Consensus for Worldwide End-of-Life Practice for Patients in Intensive Care Units (WELPICUS) study. Am J Respir Crit Care Med 2014;190(8):855-866. https://doi.org/10.1164/rccm.201403-0593CC

123. Hope T, McMillan J, Hill E. Intensive care triage: Priority should be independent of whether patients are already receiving intensive care. Bioethics 2012;26(5):259-266. https://doi. org/10.1111/j.1467-8519.2010.01852.x

124. Hodgson RE, Hardcastle TC. South Africa: Where have we been? In: Crippen DW, ed. ICU resource allocation in the new millennium: Will we say 'No'? New York: Springer-Verlag, 2013:75-88.

125. Haggstrom M, Asplund K, Kristiansen L. Important quality aspects in the transfer process. Int J Health Care Qual Assur 2014;27(2):123-139. https://doi.org/10.1108/ijhcqa-09-2012-0090

126. Daniels N, Sabin J. Limits to health care: Fair procedures, democratic deliberation, and the legitimacy problem for insurers. Philos Public Aff 1997;26(4):303-350.

127. Calandra T, Cohen J. The international sepsis forum consensus conference on definitions of infection in the intensive care unit. Crit Care Med 2005;33(7):1538-1548.

128. Christian MD, Hamielec C, Lazar NM, et al. A retrospective cohort pilot study to evaluate a triage tool for use in a pandemic. Crit Care 2009;13(5):R170. https://doi.org/10.1186/cc8146

129. Daugherty EL, Branson R, Rubinson L. Mass casualty respiratory failure. Curr Opin Crit Care 2007;13(1):51-56. https://doi.org/10.1097/MCC.0b013e3280129979

130. Ritvo P, Perez DF, Wilson K, et al. Canadian national surveys on pandemic influenza preparations: Pre-pandemic and peri-pandemic findings. BMC Public Health 2013;13(1):271. https://doi.org/10.1186/1471-2458-13-271

131. Cheung W, Myburgh J, McGuinness S, et al. A cross-sectional survey of Australian and New Zealand public opinion on methods to triage intensive care patients in an influenza pandemic. Crit Care Resusc 2017;19(3):254.

132. Silva DS, Gibson JL, Robertson A, et al. Priority setting of ICU resources in an influenza pandemic: A qualitative study of the Canadian public's perspectives. BMC Public Health 2012;12(1):241. https://doi.org/10.1186/1471-2458-12-241

133. Hawryluck L. Ethics review: Position papers and policies--are they really helpful to front-line ICU teams? Crit Care 2006;10(6):242. https://doi.org/10.1186/cc5095

134. Kleinpell RM. Randomized trial of an intensive care unit-based early discharge planning intervention for critically ill elderly patients. Am J Crit Care 2004;13(4):335-345.

135. Daly K, Beale R, Chang RW. Reduction in mortality after inappropriate early discharge from intensive care unit: Logistic regression triage model. BMJ 2001;322(7297):1274-1276.

136. Ho KM, Dobb GJ, Lee KY, et al. The effect of comorbidities on risk of intensive care readmission during the same hospitalization: A linked data cohort study. J Crit Care 2009;24(1):101-107. https://doi.org/10.1016/j.jcrc.2007.11.015

137. Wagner J, Gabler NB, Ratcliffe SJ, et al. Outcomes among patients discharged from busy intensive care units. Ann Intern Med 2013;159(7):447-455. https://doi.org/10.7326/00034819-159-7-201310010-00004

138. Rosenberg AL, Hofer TP, Hayward RA, Strachan C, Watts CM. Who bounces back? Physiologic and other predictors of intensive care unit readmission. Crit Care Med 2001;29(3):511-518

139. Moreno R, Miranda DR, Matos R, Fevereiro T. Mortality after discharge from intensive care: The impact of organ system failure and nursing workload use at discharge. Intensive Care Med 2001;27(6):999-1004.

140. Azoulay E, Adrie C, De Lassence A, et al. Determinants of postintensive care unit mortality: A prospective multicenter study. Crit Care Med 2003;31(2):428-432. https://doi. org/10.1097/01.Ccm.0000048622.01013.88

141. Vasilevskis EE, Kuzniewicz MW, Cason BA, et al. Predictors of early postdischarge mortality in critically ill patients: A retrospective cohort study from the California Intensive Care Outcomes project. J Crit Care 2011;26(1):65-75. https://doi.org/10.1016/j.jcrc.2010.06.010

142. Kaben A, Correa F, Reinhart K, et al. Readmission to a surgical intensive care unit: Incidence, outcome and risk factors. Crit Care 2008;12(5):R123. https://doi.org/10.1186/cc7023

143. Ponzoni CR, Correa TD, Filho RR, et al. Readmission to the intensive care unit: Incidence, risk factors, resource use, and outcomes. A retrospective cohort study. Ann Am Thorac Soc 2017;14(8):1312-1319. https://doi.org/10.1513/AnnalsATS.201611-851OC

144. Oerlemans AJ, van Sluisveld N, van Leeuwen ES, et al. Ethical problems in intensive care unit admission and discharge decisions: A qualitative study among physicians and nurses in the Netherlands. BMC Med Ethics 2015;16:9. https://doi.org/10.1186/s12910-015-0001-4 
145. Zimmerman JE, Wagner DP, Draper EA, Knaus WA. Improving intensive care unit discharge decisions: Supplementing physician judgment with predictions of next day risk for life support. Crit Care Med 1994;22(9):1373-1384.

146. Gajic O, Malinchoc M, Comfere TB, et al. The Stability and Workload Index for Transfer score predicts unplanned intensive care unit patient readmission: Initial development and validation. Crit Care Med 2008;36(3):676-682. https://doi.org/10.1097/ccm.0b013e318164e3b0
147. Heidegger CP, Treggiari MM, Romand JA. A nationwide survey of intensive care unit discharge practices. Intensive Care Med 2005;31(12):1676-1682. https://doi.org/10.1007/ discharge practices.

148. van Sluisveld N, Bakhshi-Raiez F, de Keizer N, et al. Variation in rates of ICU readmission and post-ICU in-hospital mortality and their association with ICU discharge practices. BMC
Health Serv Res 2017;17(1):281. https://doi.org/10.1186/s12913-017-2234-z 